\title{
A self-branched lamination of hierarchical patronite nanoarchitectures on carbon fiber cloth as novel electrode for ionic liquid electrolyte-based high energy density supercapacitors
}

\author{
Ramu Manikandan, ${ }^{a}$ Chellan Justin Raj, ${ }^{b}$ Goli Nagaraju, ${ }^{\mathrm{c}}$ J. Puigdollers, ${ }^{\mathrm{d}}$ C. Voz, ${ }^{\mathrm{d}}$ Byung Chul \\ $\mathrm{Kim}^{\mathrm{a} *}$ \\ ${ }^{a}$ Department of Printed Electronics Engineering, Sunchon National University, 255, Jungang-ro, \\ Suncheon-si, Jellanamdo, 57922, Republic of Korea. \\ ${ }^{b}$ Department of Chemistry, Dongguk University-Seoul, Jung-gu, Seoul-04620, Republic Korea \\ ${ }^{c}$ Department of Chemical Engineering, College of Engineering, Kyung Hee University, 1732, \\ Deogyeong-daero, Gihung-gu, Yongin-si, Gyeonggi-do 17104, Republic of Korea. \\ ${ }^{d}$ Dept. Enginyeria Electrònica Universitat Politècnica Catalunya Barcelona, Spain. \\ * Corresponding author. \\ Email address: bckim@ @scnu.ac.kr (B. C. Kim)
}




\begin{abstract}
The development of rationally designed binder-free metal chalcogenides decorated flexible electrodes are of paramount importance for advanced energy storage devices owing to their characteristic advantages like high electroactivity, suppressed dead-volume, rapid charge transportation and high capacitance. Herein, we have facilely fabricated binder-free patronite $\left(\mathrm{VS}_{4}\right)$ nanoflowers decorated on carbon cloth (CC) with robust adhesion to use as a binder-free electrode for supercapacitors. The optimal electrode with an appropriate growth concentration (VS4-CC@VS-3) showed a considerable pseudocapacitance performance in ionic liquid (IL) electrolyte (i.e., 1-ethyl-3-methylimidazolium trifluoromethanesulfonate) with high potential window. Utilizing VS 4 -CC@VS-3 as both positive and negative electrodes, IL-based symmetric supercapacitor (SSC) was assembled, which demonstrated a high areal capacitance $\left(\mathrm{C}_{\mathrm{ac}}\right)$ value of $536 \mathrm{mF} \mathrm{cm}^{-2}\left(206 \mathrm{~F} \mathrm{~g} \mathrm{~g}^{-1}\right)$ at $1 \mathrm{~mA} \mathrm{~cm}^{-2}$. Moreover, the device displayed maximum energy and power densities of $74.4 \mu \mathrm{Wh} \mathrm{cm} \mathrm{cm}^{-2}\left(28.6 \mathrm{Wh} \mathrm{kg}^{-1}\right)$ and $10154 \mu \mathrm{W} \mathrm{cm}-2$ (9340 $\left.\mathrm{W} \mathrm{kg}^{-1}\right)$ with excellent capacitance retention of $93 \%$ after long-term cycles. Following, the device stably energizes various portable electronic applications for a long time owing to its high-energy storage properties, which make the fabricated composite material open up news for the fabrication of fabrics supported chalcogenides for energy storage devices.
\end{abstract}

Keywords: Hydrothermal technique, $\mathrm{VS}_{4}$, ionic liquid, supercapacitor, binder-free electrode. 


\section{Introduction}

Supercapacitors (SCs) are gaining greater attention in the recent energy storage technology due to their high-power density and long cycle life.$^{[1],[2]}$ However, they require an enormous amount of power to work as an autonomous or complement distinctive vitality sources such as batteries and fuel cells. ${ }^{[3]}$ Supercapacitors are commonly divided into two types according to their charge storage mechanisms, namely non-faradic electrical double-layer capacitors, which store the energy via charge accumulation at the porous electrode-electrolyte interface. On the other hand, metal oxide/sulfides-based pseudocapacitors store high energy, which is mainly originated by the reversible faradaic charge storage mechanism. ${ }^{[4]}$ In recent decades, various types of transition metal sulfides (TMSs) have been examined beyond the state-of-art-of materials, which showed exceptional energy storage performance compared to the former generation materials, including metal oxides and carbon-based materials. The materials such as $\mathrm{MoS}_{2},{ }^{[5]} \mathrm{WS}_{2},{ }^{[6]} \mathrm{NiS},{ }^{[7]} \mathrm{VS}_{4},{ }^{[8]}$ $\mathrm{VS}_{2},{ }^{[9]}$ and $\mathrm{CoS}^{[10]}$ have been the subject of intense research in pseudocapacitors. ${ }^{[11]}$ Particularly, the transition metal sulfide-like vanadium sulfides $\left(\mathrm{VS}_{4}\right.$ or $\left.\mathrm{VS}_{2}\right)$ exhibits an immense interest among the researchers owing to its promising energy-storage activities. ${ }^{[12]}$ Among the various vanadium sulfides, the $\mathrm{VS}_{4}$ consisted of two $\mathrm{S}_{2}{ }^{2-}$ dimers and unusual linear-chain structure where the oxidation state of vanadium is similar to $\mathrm{VS}_{2}$ structure. Moreover, the structure of $\mathrm{VS}_{4}$ varies to prevent the bundle formation of nanosheets and which effectively improves the surface area of the material for better electrochemical properties. ${ }^{[13]}$ Recently, $\mathrm{VS}_{4}$ nanostructures with various morphologies, such as urchin-like, octopus-like, sea grass-like, and nano-dendrites have been synthesized and applied especially as the anode materials in lithium-ion batteries. ${ }^{[14]}$ Generally, large scale synthesis of $\mathrm{VS}_{4}$ with high purity is complicated due to the necessity of precise controlled partial pressure of sulfur during sulfurization and existence of various 
nonstoichiometric phases of vanadium sulfides with different oxidation states. ${ }^{[13]}$ However, the pure form of patronite- $\mathrm{VS}_{4}$ nanostructures can be synthesized via template-assisted growth method over graphene, CNTs, carbon fibers etc. ${ }^{[12 a, 15]}$ This reveals that the $\mathrm{VS}_{4}$ nanostructures have better growth affinity on carbonaceous materials. Therefore, an attempt was made to grow pure phase of $\mathrm{VS}_{4}$ on conducting carbon fiber cloth (CC), which is an excellent substrate for designing a lightweight and flexible supercapacitor electrode. Since 3D structure of CC can be anticipated to facilitate a fast charge transfer and enhances the accessibility of the electrolytic ions into the electrode material. ${ }^{[16]}$ Apart from this, the significantly high capacity and capacity retention of the $\mathrm{VS}_{4}{ }^{[17]}$ can act as a potential pseudocapacitance electrode material for the development of supercapacitors. Hence, for the first time, a binder-free strategy has been adopted to grow $\mathrm{VS}_{4}$ as a pure phase on conducting carbon fiber cloth and utilized for the fabrication of symmetric supercapacitor in an ionic liquid electrolyte.

To enhance the energy density $\left(\mathrm{E}_{\mathrm{d}}\right)$ of supercapacitors, currently, the researchers have adopted two major strategies. Namely, synthesize of self-assembled binder-free electrode materials on the conductive substrate (such as Ni-foam, carbon cloth, and stainless-steel mesh, etc.,), and utilization of ionic liquid or organic electrolytes. The binder-less electrode materials on the current collector is favorable for affording more active sites to increase the specific capacitance $\left(\mathrm{C}_{\mathrm{sc}}\right)$ of the SCs. ${ }^{[18]}$ On the other hand, the ionic or organic electrolytes can increase the maximum operating potential widow of devices, and which undoubtedly exalt the energy storage properties of supercapacitors. ${ }^{[19]}$ Recently, ionic liquids (ILs) are considered as a major domain in the field of electrochemistry due to their high ionic mobility, the flexibility of ions and broad potentials. Although the ILs are the first choice for elective solvents or electrolytes, their applications as simple solvents/electrolytes in the electrochemical system are way beyond or 
imagination. ${ }^{[20]}$ The recent studies established two specific reasons of ILs as a potential electrolyte for supercapacitors, especially in double-layer charging. ${ }^{[21]}$ The first reason is a primary task of the electrolyte to provide charge species at the electrode/electrolyte interface instead of diffusion of specific electroactive species and the other is the wide stable potential window of ILs which guarantees high energy densities even greater and safer than the organic electrolytes. ${ }^{[22]}$ Apart from these practical applications, when IL is used as a solvent-free media and it can act as straightforward systems for fundamental studies to understand the nature of electrode/electrolyte interface in supercapacitors ${ }^{[23]}$. The emerging interest in the utilization of ILs is due to the practical potentials that it offers, and unfortunately, a limited number of fundamental studies (mostly theoretical) are available focusing on the electrode/electrolyte interface of supercapacitors in ILs. ${ }^{[2]}$ However, the ILs reveal to have very promising strategies to be employed in supercapacitors due to their structural flexibility to functionalize them to present specific contacts with the surface or redox performance. ${ }^{[21]}$ Besides, the ILs have better stability in high temperature due to its high melting point and high boiling point, which certifies a prosperous safety of the device. However, the pseudocapacitive performance of transition metal sulfides/oxides in ILs is infrequently reported. Subsequently, there is a huge interest to develop novel metal chalcogenides for high-performance supercapacitors due to its low-cost, naturally abundant and environmental benignity. ${ }^{[16 b]}$ Thus, choosing appropriate IL electrolyte for these materials can effectively improve the operating voltage of the metal chalcogenide-based SCs with a considerable increase in the energy density.

In this work, a novel flower-like $\mathrm{VS}_{4}$ (patronite) nanostructures were grown on carbon cloth (CC) using the one-step hydrothermal method without the aid of any polymeric binders. Further, the effect of various precursor concentrations on the growth, morphology and 
electrochemical performance were studied. The fabricated growth reagents/concentrationdepended binder-free $\mathrm{VS}_{4}$ electrodes were initially tested in a three-electrode system using ionic liquid electrolyte (1 M 1-ethyl-3-methylimidazolium trifluoromethanesulfonate ([EMIM][OTf])), which demonstrates that the $\mathrm{VS}_{4}$ electrode has a considerable affinity towards the IL with a pseudocapacitive nature of energy storage process. In addition, the symmetric supercapacitors were assembled using different concentration-dependent $\mathrm{VS}_{4}$ nanostructures based electrodes in [EMIM][OTf] electrolyte with an operating voltage of 2V. Among these, the VS4-CC@VS3//VS4-CC@VS-3 symmetric device displays a high $\mathrm{C}_{\mathrm{ac}}$ of $536 \mathrm{mF} \mathrm{cm} \mathrm{cm}^{-2}$ at $1 \mathrm{~mA} \mathrm{~cm}$. Furthermore, the device exhibited high energy density of $74.4 \mu \mathrm{Wh} \mathrm{cm}^{-2}$ and maximum power density of $10154 \mu \mathrm{W} \mathrm{cm}-2$ with better capacitance maintenance ( 93\%) after 1000 cycles in [EMIM][OTf] electrolyte. The electrochemical performances of the $\mathrm{VS}_{4}-\mathrm{CC} @ \mathrm{VS}-3 / / \mathrm{VS}_{4}-$ CC@VS-3 device was comparatively studied and discussed in detail. . 


\section{Results and Discussion}

The schematic representation in Figure 1 illustrates the one-step growth of hierarchical $\mathrm{VS}_{4}$ nanostructures on $\mathrm{CC}$ by hydrothermal technique. As a well-known substrate, $\mathrm{CC}$ has received significant attention in designing energy storage devices owing to its, 3D architecture, great flexibility, good thermal resistivity and high conductivity. Utilizing such a feasible substrate, the $\mathrm{VS}_{4}$ nanostructures were densely grown and directly used as the supercapacitor electrode. During the $\mathrm{VS}_{4}$ growth process, the placement of the growth substrate inside the hydrothermal reactor is crucial to control the optimum growth of electroactive material over CC. As represented in Figure S1 and Figure 1, the vertically mounted substrate in growth solution showed a uniform and controlled growth of flower-like $\mathrm{VS}_{4}$ nanostructures with better adhesion on $\mathrm{CC}$ substrate. But, the horizontally placed substrate evidenced the vigorous deposition of agglomerated $\mathrm{VS}_{4}$ nanostructures with poor adhesion on the $\mathrm{CC}$ fibers. To corroborate the above observation, the morphological aspects of vertically and horizontally grown substrates are displayed in Figure $\mathbf{3}$ and Figure S2. Moreover, the CC substrate was supported with a glass slide (Figure 1) for better vertical alignment and also determine the growth of $\mathrm{VS}_{4}$ nanostructures on the exposed $\mathrm{CC}$ surface. 
Figure 1. Schematic illustration displaying the synthesis process of ferox fruit-like patronite $\left(\mathrm{VS}_{4}\right)$ nanostructures on flexible carbon cloth under the $\mathrm{pH}$ controlled growth medium.

Figure 2 a (i, ii) displays the photographic images of growth solutions and the fabricated electrodes. The color of growth solution varies from light blue to dark blue, which gives a strong influence on the growth rate of $\mathrm{VS}_{4}$ concerning the concentration of the precursor. Moreover, the increase in concertation slightly increases the acidic nature of the growth solution and possess an additional tendency to converts the hydrophobic CC into more hydrophilic. This evidently enables the better growth of $\mathrm{VS}_{4}$ nanostructures on $\mathrm{CC}$, as shown in Figure 2(a)(ii). (the $\mathrm{CC}$ is 
fully covered with darker deposition of black colored $\mathrm{VS}_{4}$ ). Further, the mechanical durability of the $\mathrm{VS}_{4}$ laminations on $\mathrm{CC}$ was ensured by subsequent bending and twisting experiments. But no visible dispersion of materials was observed from the electrode, which confirms better adhesion of $\mathrm{VS}_{4}$ on $\mathrm{CC}$ and great mechanical durability of the fabricated electrode (Figure 2(a)(iii)).

Figure 2(b) presents the X-ray diffraction (XRD) patterns of the fabricated $\mathrm{VS}_{4-}$ CC@VS-1, VS 4 -CC@VS-2,VS4-CC@VS-3 samples and the bare CC substrate. The bare CC (black curve) shows two significant broad diffraction peaks at $26.3^{\circ}$ and $44.4^{\circ}$, which coincide to (002) and (101) diffraction planes of the standard hexagonal phase of the crystalline carbon (JCPDS no. 75-1621). ${ }^{[25]}$ The additional diffraction peaks observed in $\mathrm{VS}_{4}-\mathrm{CC} @ \mathrm{VS}-1$ (blue), VS4-CC@VS-2 (orange) and VS 4 -CC@VS-3 (green) samples were indexed to the monoclinic $\mathrm{VS}_{4}$ phase, corresponding to (110), (020), (123), (132), (114), (-215), and (332) planes (JCPDS No. 072-1294, space group: I 2/c), ${ }^{[26]}$. The VS 4 -CC@VS-1 sample shows noisily and low intense peaks represent the poor crystallinity and less distribution of $\mathrm{VS}_{4}$ on $\mathrm{CC}$, which is ascribed to the low concentration of growth solution in the growth process. Moreover, the VS 4 -CC@VS-2 sample displays two additional impurity peaks, which can be assigned to the $\mathrm{V}_{2} \mathrm{~S}_{3}$ (JCPDS No. 19-1407) and sulfur (JCPDS No. 65-1101) formed due to the improper concentration of growth solution. Further increasing the concentration of growth solution, the $\mathrm{VS}_{4}-\mathrm{CC} @$ VS-3 XRD profile shows the formation of pure crystalline phase of $\mathrm{VS}_{4}$ with well-defined narrow and sharp diffraction peaks at $15.78^{\circ}$ and $17.01^{\circ}$, corresponds to the (110) and (020) crystal planes, which discloses the highly crystalline and dense growth of $\mathrm{VS}_{4}$ on CC. These substantial differences in XRD patterns of the VS 4 expose to the various concentration of growth solution have an essential effect on the structural and crystallinity of the samples. The chemical oxidation states of $\mathrm{V}$ and $\mathrm{S}$ in the $\mathrm{VS}_{4}$ nanostructure on $\mathrm{CC}$ surface was investigated using $\mathrm{X}$-ray 
photoelectron spectroscopy (XPS), the corresponding results are presented in Figure 2(c-g). Figure 2(c) displays the survey spectrum represents the presence of carbon (C), vanadium (V), sulfide (S) and oxygen (O) atoms in the VS4-CC@VS-3 sample. The carbon peak detected in the spectrum is mainly originated from the CC substrate. The C 1s spectrum (Figure 2(d)) was deconvoluted into three different components at $284.4,285.8$ and $287.554 \mathrm{eV}$, corresponds to the overlapping $\mathrm{C}-\mathrm{C}$ bonds, $\mathrm{C}-\mathrm{OH}$ bands, and $\mathrm{C}=\mathrm{O}$ (carbonyl) bonds, ${ }^{[27]}$ respectively. The XPS peaks observed at $523.4 \mathrm{eV}$ and $516.2 \mathrm{eV}$ (Figure 2(e)) are assigned to the spin-orbit splitting $V 2 p_{3 / 2}$ and $V 2 p_{1 / 2}$ of $V 2 p$ energy state. The slight shift in the binding energies indicates the reasonably high $\mathrm{V}^{4+}$ state than $\mathrm{V}^{5+}$ (since the $\mathrm{V} 2 \mathrm{p}$ peak of $\mathrm{V}^{5+}$ are normally placed at $\sim 517.2$ and $\sim 524.5 \mathrm{eV}$ ) signifying the influence of $\mathrm{V}^{4+}$ in $\mathrm{VS}_{4}$ nanostructures. ${ }^{[26]}$ In Figure 2(f), S $2 \mathrm{p}$ spectrum reveals two peaks at $162.3 \mathrm{eV}$ and $163.5 \mathrm{eV}$, which represents the spin-orbit splitting of sulfur $2 \mathrm{p}_{3 / 2}$ and $2 \mathrm{p}_{1 / 2}$ of the $\mathrm{S}^{-2}$ dimer in $\mathrm{VS}_{4} \cdot{ }^{[12 \mathrm{a}]}$ Meanwhile, the resultant $\mathrm{O} 1 \mathrm{~s}$ peak observed in Figure 2(g), can be deconvoluted into two peaks at $530.4(\mathrm{C}-\mathrm{O})$ and $531.6(\mathrm{C}-\mathrm{O}-\mathrm{H}) \mathrm{eV}$, which is due to the $\mathrm{C}$ functionalities from $\mathrm{CC}$ conductive medium associated with moisture oxygen molecules. ${ }^{[28]}$ 


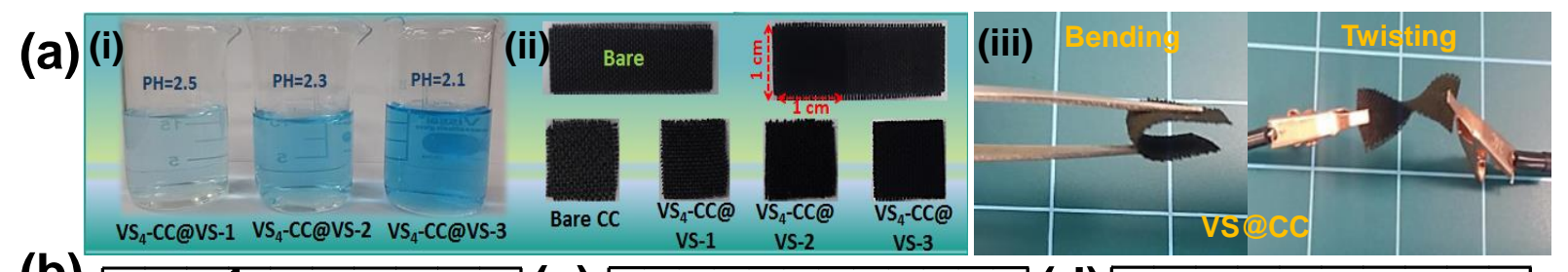

(b)

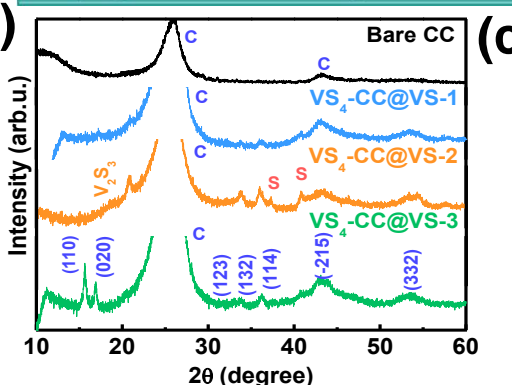

(e)

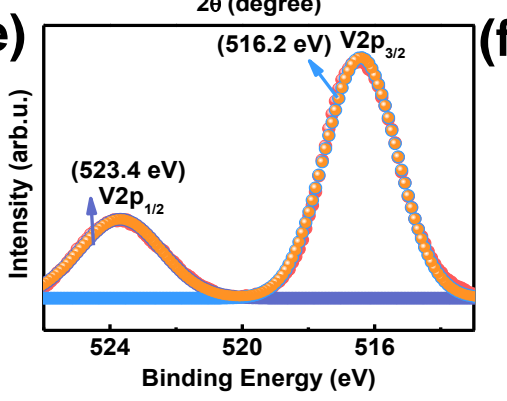

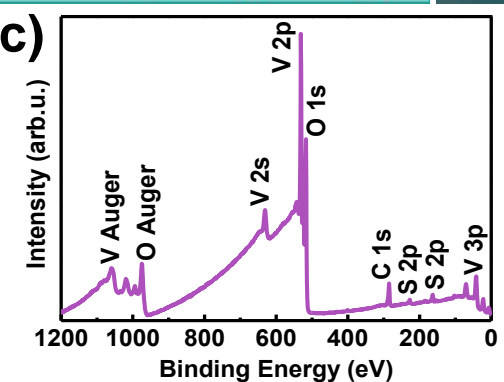

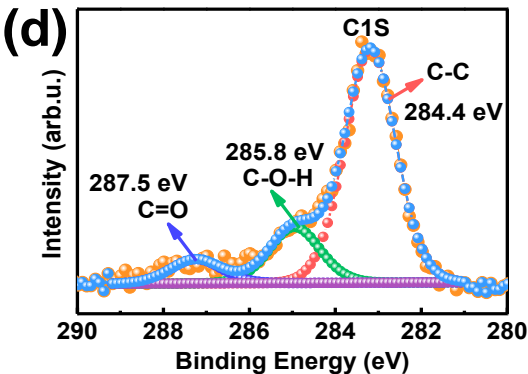

(f)

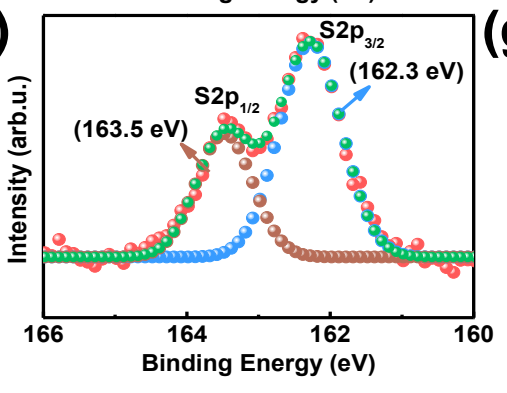

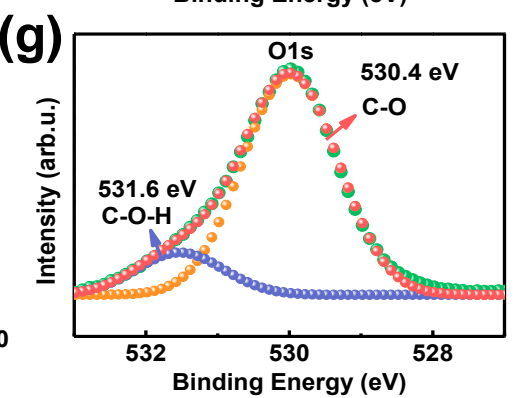

Figure 2 (a) (i-ii) Photographic images of different concentration growth solutions and prepared electrodes (bare CC, VS4-CC@VS-1, VS4-CC@VS-2, and VS4-CC@VS-3 electrodes), (b) XRD patterns of bare CC, VS 4 -CC@VS-1, VS 4 -CC@VS-2, and VS 4 -CC@VS-3, (c) XPS survey spectrum of VS 4 -CC@VS-3 sample, (d-g) High-resolution XPS spectra of C, V, S and O region of the $\mathrm{VS}_{4}-\mathrm{CC} @ \mathrm{VS}-3$ sample.

The morphology of the synthesized samples under different growth concentrations are examined using field-emission scanning electron microscopy (FE-SEM), as shown in Figure 3. Figure 3(a) (i-iii) shows the FESEM images of $\mathrm{VS}_{4}-\mathrm{CC} @ \mathrm{VS}-1$, which reveal $\mathrm{VS}_{4}$ had nanospike like agglomerated particles, which are irregularly scattered over the surface of CC substrate. Further increasing the concentration of growth solution to twice, the $\mathrm{VS}_{4}-\mathrm{CC} @ \mathrm{VS}-2$ sample (Figure 3(b)(i-iii)) shows an increased growth rate of $\mathrm{VS}_{4}$ on the surface of CC. Moreover, the discrete nanospike bunches as observed in the earlier case have well incorporated 
with each other introducing the formation of flower-like morphologies. However, the $\mathrm{VS}_{4}$ flower- like nanostructures located improper alignment over the $\mathrm{CC}$ surface and most of the $\mathrm{CC}$ surface areas are opened. So, the static concentration of the reaction is found inadequate for the dense growth of $\mathrm{VS}_{4}$. Hence, the growth solution concentration was further doubled than that of $\mathrm{VS}_{4}$-CC@VS-2 solution and the resultant FESEM images of $\mathrm{VS}_{4}$-CC@VS-3 confirmed the appropriate mass of the precursor concentration in the growth solution to attain an enriched growth of the $\mathrm{VS}_{4}$ nanoflowers as depicted in Figure 3(c)(i-iii). The enriched $\mathrm{VS}_{4}$ nanoflowers slightly resemble a datura ferox fruit-like morphology. This densely grown $\mathrm{VS}_{4}$ flower-like morphology over the $\mathrm{CC}$ substrate can provide larger electroactive sites for better charge-storage process.

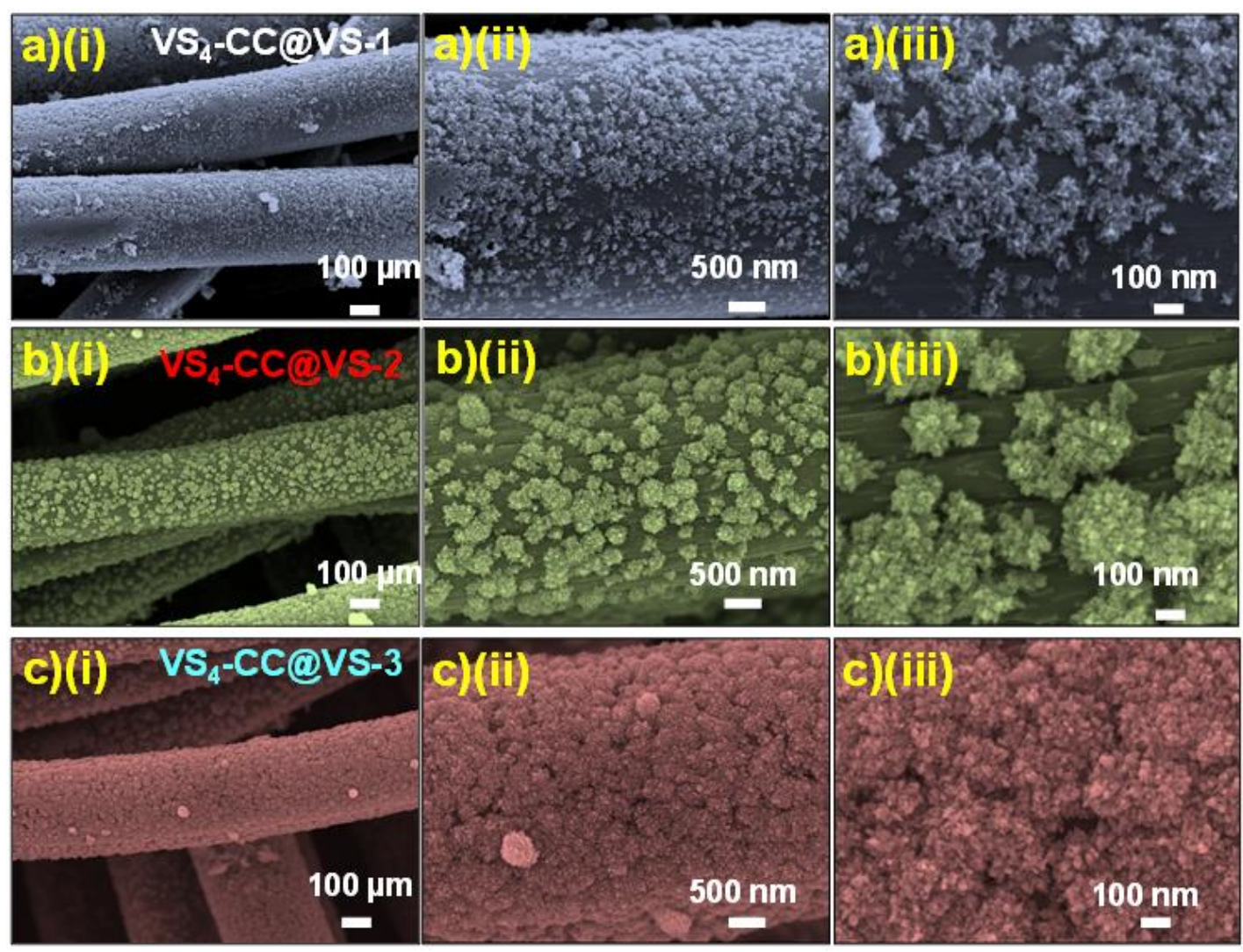


Figure 3 FE-SEM images of (a) VS4-CC@VS-1, (b) VS4-CC@VS-2, and (c) VS4-CC@VS-3 samples at different magnifications.

In order to examine the purity and proper distribution of the material on CC, the Energydispersive X-ray spectroscopy (EDX) and elemental mapping images were carried out, as shown in In Figure 4(a) and (b). The EDX spectrum showed that the material consists of vanadium (V), sulfur (S), oxygen (O) and carbon (C), representing the successful growth of $\mathrm{VS}_{4}$ on CC after the hydrothermal process. As shown in Figure $4 \mathbf{b}(\mathbf{( i )}$ and (ii)), the corresponding EDX discrete element mapping reveals the signals of V, S and C elements in the VS4-CC@VS-3 sample, representing the presence of $\mathrm{VS}_{4}$ and $\mathrm{C}$ from the $\mathrm{CC}$ substrate. Moreover, the $\mathrm{V}$ and $\mathrm{S}$ components are uniformly distributed throughout the $\mathrm{CC}$ substrate without any visible impurities. These EDX mapping results confirmed that the $\mathrm{VS}_{4}$ nanostructures were strongly bonded on the surface of the CC. Moreover, the morphology of the $\mathrm{VS}_{4}$ flower-like nanostructures were further examined using a transmission electron microscope (TEM) analysis, as given in Figure 4c(i-ii). The low and high magnification TEM images shows that the $\mathrm{VS}_{4}$ nanostructures were obtained through a self-assembly of nanospikes, which were closed packed together to form a flower-like morphologies. Each of these flowers had a size ranges from $~ 200-300 \mathrm{~nm}$, respectively. The asobtained $\mathrm{VS}_{4}$ flower like nanostructures on $\mathrm{CC}$ may permit the electrolyte ions efficiently into their interiors and activate the entire material towards superior electrochemical performance. 

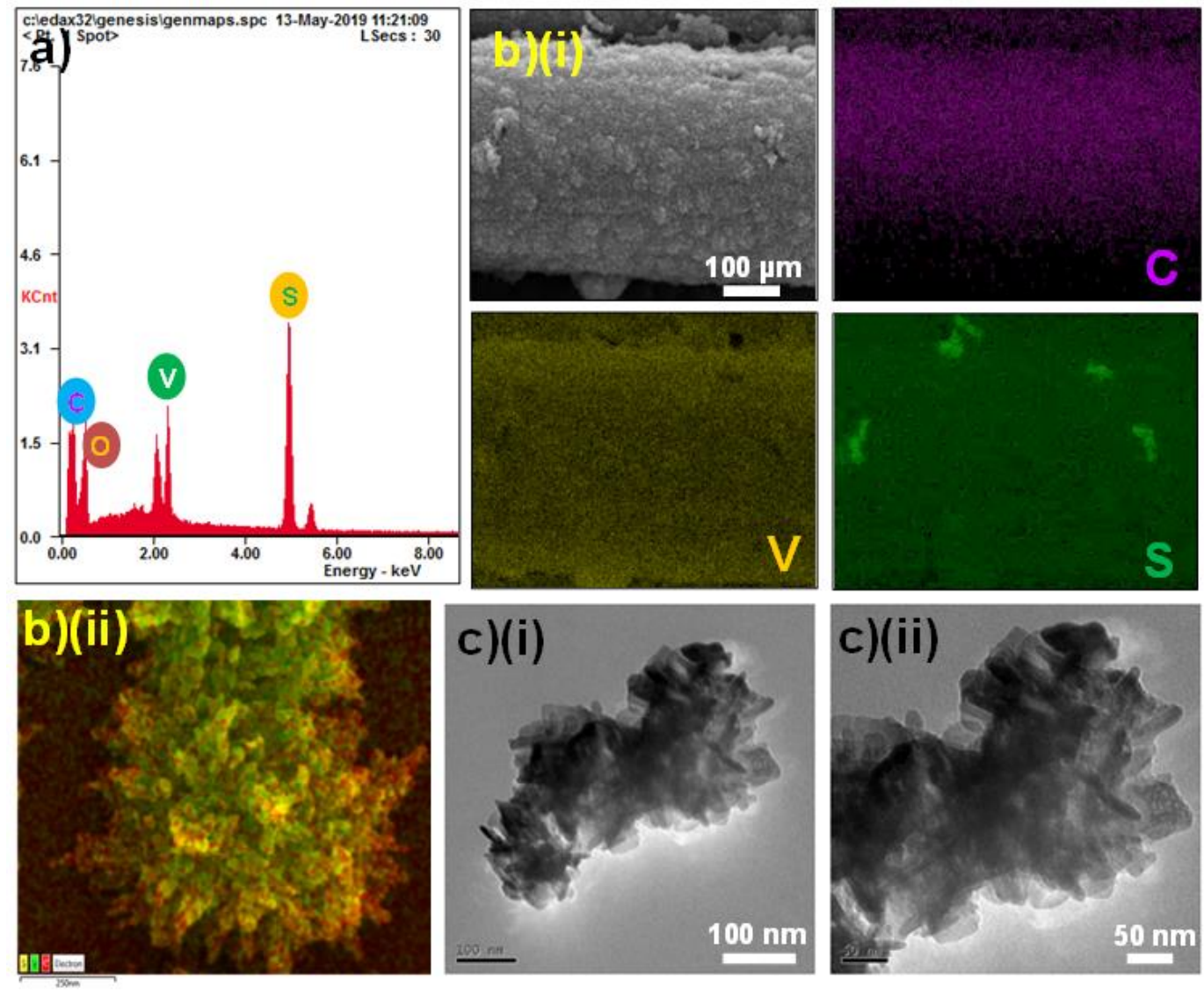

Figure 4 (a) EDX spectrum of $\mathrm{VS}_{4}-\mathrm{CC} @ \mathrm{VS}-3$ sample representing the presence of the V, S and C. (b)(i-ii) elemental mapping images of the $\mathrm{V}$ (yellow), $\mathrm{S}$ (green) and $\mathrm{C}$ (purple) in $\mathrm{VS}_{4}$ CC@VS-3 sample. (c)(i-ii) the different magnification TEM images of the dispersed $\mathrm{VS}_{4}$ CC@VS-3 sample.

The electrochemical behavior of the $\mathrm{VS}_{4}-\mathrm{CC} @ \mathrm{VS}-3$ electrode was initially tested in a threeelectrode cell with 1 M 1-ethyl-3-methylimidazolium trifluoro methane sulfonate in acetonitrile ([EMIM][OTf]) ionic liquid electrolyte. Figure S3(a) displays the cyclic voltammograms (CVs) of VS3@CC electrode measured at various scan rates from 5 to $100 \mathrm{mV} \mathrm{s}^{-1}$ scan rate in the potential range of -0.5 to $1.5 \mathrm{~V}$. The $\mathrm{CVs}$ of $\mathrm{VS}_{4}-\mathrm{CC} @ \mathrm{VS}-3$ electrode shows broad redox peaks, which attributes to the $[\mathrm{EMIM}]^{+}$intercalation/deintercalation process representing the pseudocapacitive behavior of the electrode. 
(a)

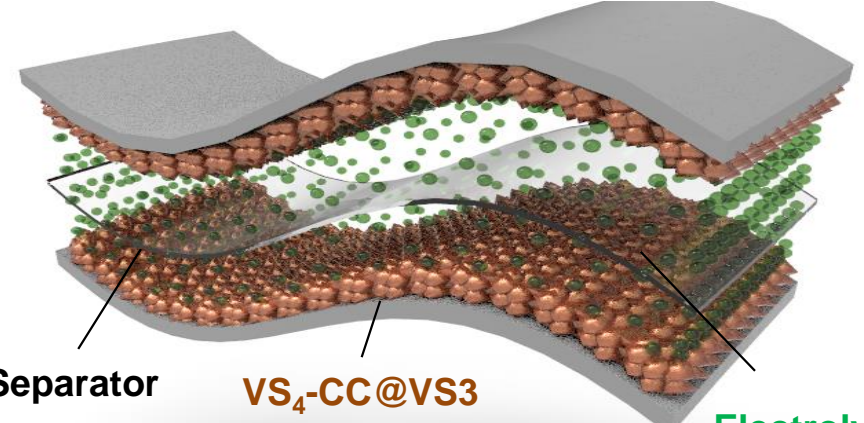

Separator $\quad \mathrm{VS}_{4}$-CC@VS3

Electrolyte (EMIM Otf)

(b)

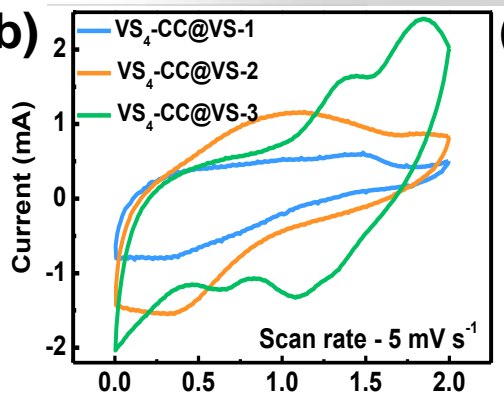

(e)

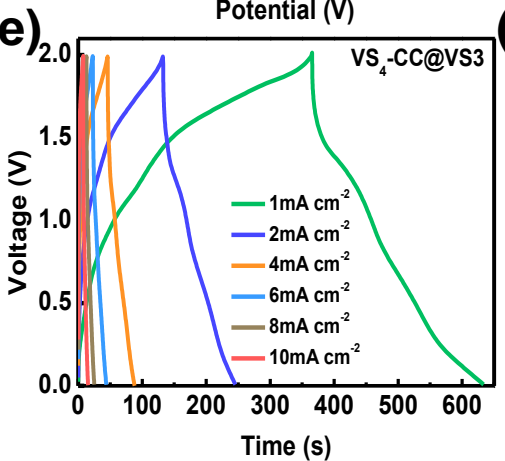

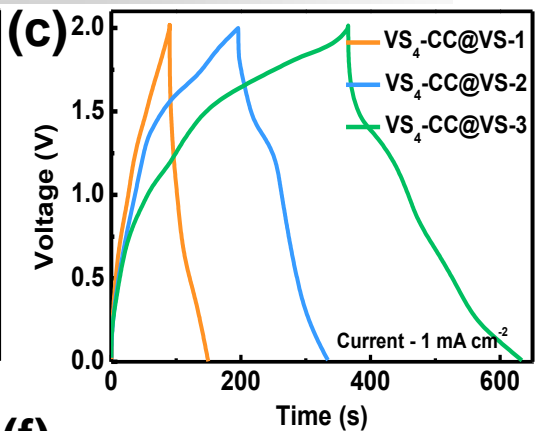

(f)

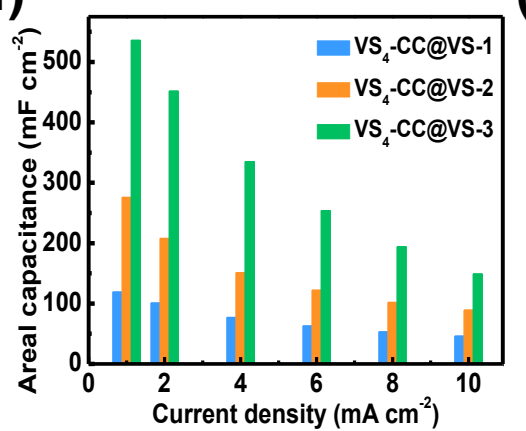

(d)

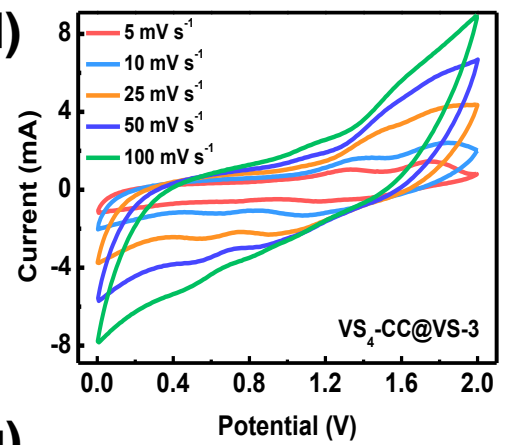

(g)

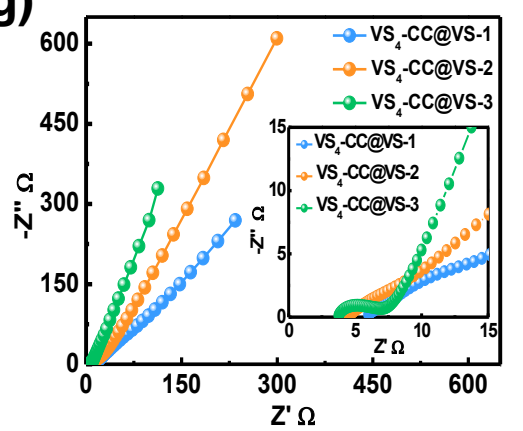

(j)
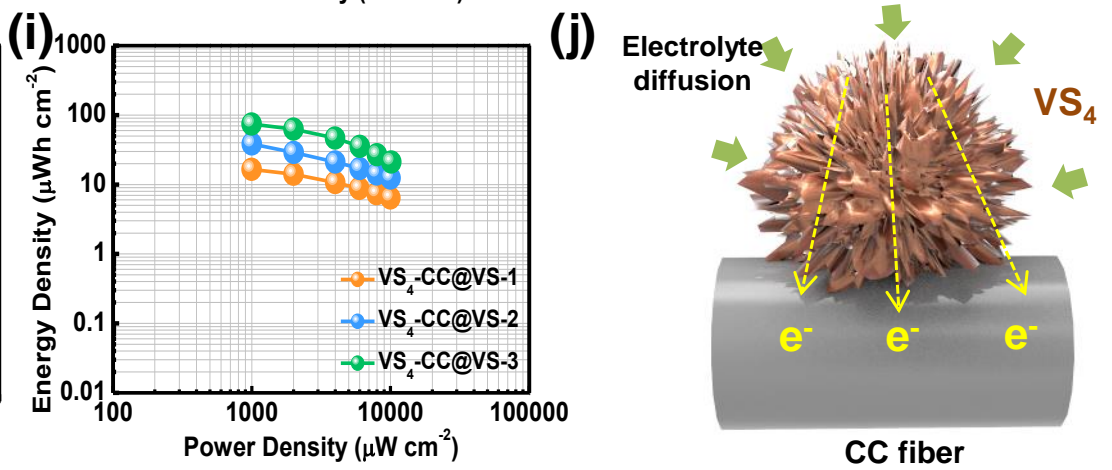

CC fiber

\section{$\mathrm{CH}_{3}$}

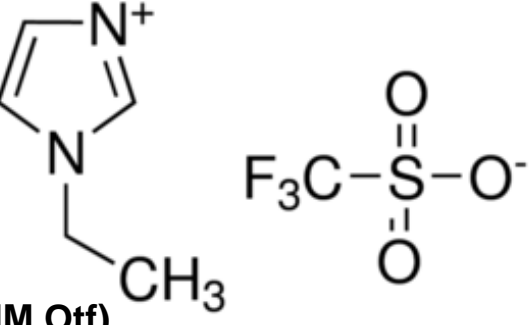

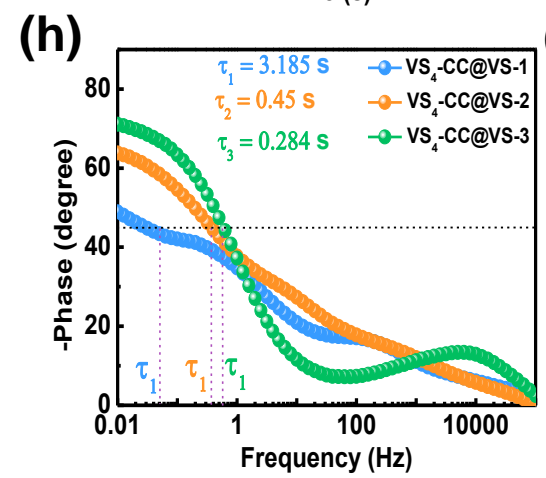

Figure 5 (a) Schematic illustration of the fabricated VS3@CC symmetric supercapacitor (SSC) in ionic liquid electrolyte. (b) CVs of $\mathrm{VS}_{4}-\mathrm{CC} @ \mathrm{VS}-1, \mathrm{VS}_{4}-\mathrm{CC} @ \mathrm{VS}-2$ and $\mathrm{VS}_{4}-\mathrm{CC} @ \mathrm{VS}-3$ at 5 $\mathrm{mV} \mathrm{s}^{-1}$ scan rate. (c) GCD curves of the $\mathrm{VS}_{4}-\mathrm{CC} @ \mathrm{VS}-1, \mathrm{VS}_{4}-\mathrm{CC} @ \mathrm{VS}-2$ and VS 4 -CC@VS-3 SSCs at $1 \mathrm{~mA} \mathrm{~cm}^{-2}$ current density. (d) CVs of VS4-CC@VS-3 for various scan rates. (e) GCD 
curves of VS3@CC for various current densities. (f) Areal capacitance $\left(\mathrm{C}_{\mathrm{ac}}\right)$ of VS $\mathrm{S}_{4} \mathrm{CC} @ \mathrm{VS}-1$, VS4-CC@VS-2 and VS4-CC@VS-3 for various current densities, (g) Nyquist plots of $\mathrm{VS}_{4}$ CC@VS-1, VS4-CC@VS-2 and VS4-CC@VS-3 devices. (h) Bode plots of VS4-CC@VS-1, VS 4 CC@VS-2 and VS 4 -CC@VS-3 devices. (i) Ragone plot of the fabricated VS 4 -CC@VS-1, VS4CC@VS-2 and VS4-CC@VS-3 symmetric devices. (j) Schematic illustration showing the merits of the binder-free VS4-CC@VS-3 electrode for high-performance energy storage.

Considering the practical application, the symmetrical supercapacitors (SSCs) were fabricated in $1 \mathrm{M}$ [EMIM][OTf] electrolyte utilizing the synthesized electrodes. The schematic illustration of the fabricated symmetric supercapacitor is presented in Figure 5(a). From the initial studies on the pseudocapacitive behavior of $\mathrm{VS}_{4}$ in an IL electrolyte [EMIM][OTf], it was found that the electrode demonstrated an ionic conductivity $\left(8.6-11 \mathrm{mS} . \mathrm{cm}^{-1}\right)$, viscosity $(45 \mathrm{cP})$ and electrochemical window $(4.1 \mathrm{~V})$ for the cation $\left([\mathrm{EMIM}]^{+}\right)$and anion $\left([\mathrm{OTf}]^{-}\right)$, respectively. ${ }^{[29]}$ Moreover, [EMIM][OTf] electrolyte for VS 4 -CC@ VS-3-based SCs can effectually improve the operating voltage $(2 \mathrm{~V})$ with a significantly increase in the energy density. In addition the pseudocapacitive nature of $\mathrm{VS}_{4}-\mathrm{CC} @ \mathrm{VS}-3$ electrode in an IL electrolyte depend upon the intercalation/deintercalation process of $[\mathrm{EMIM}]^{+}$cation. $^{[16 \mathrm{~b}, 16 \mathrm{c}]}$ Initially, the cell voltage of the supercapacitor was optimized by conducting CV and GCD measurements for various operating voltage using the $\mathrm{VS}_{4}-\mathrm{CC} @ \mathrm{VS}-3 / / \mathrm{VS}_{4}-\mathrm{CC} @ \mathrm{VS}-3$ SSC. The CVs of $\mathrm{VS}_{4}-\mathrm{CC} @ \mathrm{VS}-3 / / \mathrm{VS}_{4}-$ CC@VS-3 SSC tested for various potential ranges from 1 to $2 \mathrm{~V}$ at a scan rate of $25 \mathrm{mV} \mathrm{s}^{-1}$ are shown in Figure S5(a). Similarly, Figure S5(b) shows the GCD curves of the fabricated SSC under various potential ranges of 1 to $2 \mathrm{~V}$ at a constant current density of $4 \mathrm{~mA} \mathrm{~cm}$. Prominently, the curves verified that the SSC showed slightly tilted triangular profile with good capacitance performance without any evaluation. From the resultant CVs and GCD curves, the 
optimum operating voltage of the SSCs was fixed to $2 \mathrm{~V}$ for further electrochemical studies. Figure 5(b) shows the CVs of VS 4 -CC@VS-1, VS4-CC@VS-2, and VS 4 -CC@VS-3 based SSC measured at a constant scan rate $5 \mathrm{mV} \mathrm{s}^{-1}$. Comparing $\mathrm{CVs}$ of the three devices, the $\mathrm{VS}_{4-}$ CC@VS-3//VS4-CC@VS-3 device reveals greater background current with a couple of broad redox peaks and displays a quasi-rectangular profile, which signifies good pseudocapacitance property of the electrode. Moreover, the CV of VS 4 -CC@VS-3 SSC displays two sets of redox peaks, where the oxidation peaks at $+1.32 \mathrm{~V}$ and $+1.85 \mathrm{~V}$ attributes the oxidation of $\mathrm{V}^{4+}$ to $\mathrm{V}^{5+}$ and $\left(\mathrm{S}_{2}\right)^{2-}$ to $\mathrm{S}^{2-}$ and the corresponding reduction peaks observed at $+0.62 \mathrm{~V}$ and $+1.5 \mathrm{~V}$ ascribed to the consecutive reduction of $\mathrm{V}^{5+}$ to $\mathrm{V}^{4+}$ and $\mathrm{S}^{2-}$ to $\left(\mathrm{S}_{2}\right)^{2-}$ respectively. ${ }^{[8]}$ Meanwhile, the similar sets of redox peaks were not observed in the CVs of VS4-CC@VS-1, and VS $4-C C @ V S-2$ devices, but they exhibited broad redox peaks with the irregular CVs. Thus, the incomplete growths of VS4 on CC electrodes have an insufficient electrochemical active site for perform redox reactions. The high peak current values of the corresponding $\mathrm{VS}_{4}-\mathrm{CC} @ \mathrm{VS}-3$ device is mainly attributed to the dense growth of $\mathrm{VS}_{4}$ flower-like nanostructures on the $\mathrm{CC}$, which adequately increase the electroactive sites of the electrode for better redox reactions with electrolyte ions. $^{[18 c]}$ The CVs of VS4-CC@VS-3, VS4-CC@VS-2, and VS4-CC@VS-3 full cells for different scan rates $\left(5-100 \mathrm{mV} \mathrm{s}^{-1}\right)$ are presented in Figure 5(d) and Figure S5(c) and (d). From the CVs, the $\mathrm{VS}_{4}-\mathrm{CC} @ \mathrm{VS}-3$ device showed high background current with better reversibility for all the measured scan rates compared to $\mathrm{VS}_{4}-\mathrm{CC} @ \mathrm{VS}-1$ and $\mathrm{VS}_{4}-\mathrm{CC} @ \mathrm{VS}-2$ devices.

Furthermore, the electrochemical performance of the VS4-CC@VS-3 SSCs synthesized under two growth positions (i.e., vertical and horizontal) were presented in Figure S4(a). Both CV curves displayed excellent capacitive performance with quasi-rectangular profile with strong 
redox peaks, which signifying the pseudocapacitance nature of the electrodes. However, the CVs of vertically grown VS4-CC@VS-3 sample device reveal better capacitive performance with greater background current than that of horizontally grown $\mathrm{VS}_{4}-\mathrm{CC} @ \mathrm{VS}-3$ sample. Thus, a systematic growth and proper adhesion of $\mathrm{VS}_{4}$ nanostructures on $\mathrm{CC}$ could enable positive influence on exalting the electrochemically active sites and increase redox reactions. Moreover, the proper growth of $\mathrm{VS}_{4}-\mathrm{CC} @ \mathrm{VS}-3$ as a binder-free electrode decreases the internal resistance of the electrode due to the strong adhesion and dense growth architectures, which delivers rapid electron transportation for better energy storage performance.

The electrochemical performance of the devices was further test by galvanostatic chargedischarge (GCD) measurements. Figure 5(c) compares the GCD curves of VS4-CC@ VS-1, VS 4 CC@VS-2, and VS 4 -CC@VS-3-based SSCs at a constant charge/discharge current density of 1 mA cm cm $^{-2}$ The GCD profiles of VS4-CC@VS-1, VS 4 -CC@VS-2, and VS4-CC@VS-3-based SSCs exhibited nearly symmetric with slightly distorted triangular shapes, which ensure the better reversibility and pseudocapacitive nature of the materials. ${ }^{[30]}$ In addition, the GCD curve of $\mathrm{VS}_{4}$-CC@VS-3 device exhibited the highest discharge period, which highlights the better electrochemical properties compared to the other two devices. From the GCD discharge curve, the areal capacitance $\left(\mathrm{C}_{\mathrm{ac}}\right)$ of the devices was calculated using equation. (2). The devices showed a maximum $\mathrm{C}_{\mathrm{ac}}$ of $119 \mathrm{mF} \mathrm{cm}{ }^{-2}\left(\mathrm{VS}_{4}-\mathrm{CC} @ \mathrm{VS}-1\right), 277 \mathrm{mF} \mathrm{\textrm {cm } ^ { - 2 }}\left(\mathrm{VS}_{4}-\mathrm{CC} @ \mathrm{VS}-2\right)$, and $536 \mathrm{mF}$ $\mathrm{cm}^{-2}\left(\mathrm{VS}_{4}-\mathrm{CC} @ \mathrm{VS}-3\right)$, respectively. Furthermore, the GCD curves of $\mathrm{VS}_{4}$-CC@VS-1, VS 4 CC@VS-2, and VS4-CC@VS-3 SSC at various charge-discharge current densities from 1 to 10 $\mathrm{mA} \mathrm{cm}{ }^{-2}$ also reveal excellent charge storage performance of the $\mathrm{VS}_{4}$-CC@VS-3 device (Figure 5(e) and Figure 6(a) and (b)). Besides, the GCD curves show a decreasing trend of discharge time with increasing current density. Generally, under high current density, electrolyte ions have 
been stored on the outer surface of active material, which led to the poor redox process of the electrode. While at low current density, the charge storage ions utilize bulk of the active material, and provide a large number of electrolytic ions to enable the faster diffusion process. ${ }^{[31]}$ Figure 5(f) depicts the variation of areal capacitance of VS $4-C C @ V S-1, V_{4}-\mathrm{CC} @ V S-2$, and $\mathrm{VS}_{4}$ CC@VS-3 SSCs for various current densities. Among these, the VS 4 -CC@VS-3 device shown high areal capacitances of 536, 452, 335, 254, 194 and $149 \mathrm{mF} \mathrm{cm}^{-2}(206,173,135,106,82$, and $68 \mathrm{~F} \mathrm{~g}^{-1}$ ) for $1,2,4,6,8$, and $10 \mathrm{~mA} \mathrm{~cm}^{-2}$, respectively. This again confirms the dense growth of $\mathrm{VS}_{4}$ nanoflowers on $\mathrm{CC}$ surface can offer a large interaction area for the fast diffusion of electrolyte ions between the active material/electrolyte interfaces. Moreover, the fabricated SSC with VS4-CC@VS-3 electrodes replicates high areal/specific capacitance values compared to previously report metal sulfide/oxide nanostructures in various electrolytes and potential windows, as presented in Table 1. The table confirmed that the areal capacitance and specific capacitance values of the fabricated VS 4 -CC@VS-3 SSC device is comparable or even higher than that of previously reported SCs.

Electrochemical impedance spectroscopy (EIS) is one of the most crucial tools to determine the electrochemical performance of energy storage devices. The Nyquist impedance plots of $\mathrm{VS}_{4}$ CC@VS-1, VS4-CC@VS-2, and VS4-CC@VS-3 SSCs and their corresponding equivalent circuit with fit curves (fitted using Z-view software) are displayed in Figure 5(g) and Figure S7. The fitted electric circuit parameters are tabulated in Table 2. The impedance plots consist of an inclined straight line and a compressed semi-circle in the scanned frequency range. The compressed semicircle at high-frequency region is due to the combination of internal $\left(\mathrm{R}_{\mathrm{s}}\right)$ and charge transfer resistance $\left(\mathrm{R}_{\mathrm{ct}}\right)$ whereas the inclined spike at lower frequency region corresponded to the Warburg resistance $\left(\mathrm{W}_{\mathrm{R}}\right)$, respectively. Along with these resistances, two 
constant phase elements (CPE1 and CPE2) also included in the electric circuit for their non-ideal capacitive behavior. ${ }^{[32]}$ The internal resistance $R_{s}$ of the device was ascribed to the combination of ionic resistance of the electrolyte and contact resistance between the active material and the conductive medium. The $\mathrm{R}_{\mathrm{s}}$ value of VS4-CC@VS-1, VS4-CC@VS-2, and VS4-CC@VS-3 SSC devices was found to be $4.629,4.14$, and $3.765 \Omega \mathrm{cm}^{2}$. The $\mathrm{R}_{\mathrm{s}}$ values start decreases with increase in reaction solution concentration because the electroactive material $\mathrm{VS}_{4}$ is densely grown over CC substrate that readily enhances the electrical conductivity, which in turn leads to making better charge transfer reaction at the electrode/electrolyte interfaces. ${ }^{[33]}$ In addition, the investigation of wettability for bare CC, VS 4 -CC@VS-1, VS $4-C C @ V S-2$, and VS $4-C C @ V S-3$ electrodes and their values are shown table S1. The all four electrodes undergo better absorption of ILs, which may provide the great wettability and decrease the internal resistance of the working electrodes. Although, the $\mathrm{R}_{\mathrm{s}}$ values are decreases with increase the reaction solution concentration. Therefore studied for absorbed capability of electrodes verified before and after $10 \mathrm{~s}$ immersed in ILs electrolyte. The increasing values are bare CC $(0.00801 \mathrm{~g})<\mathrm{VS}_{4}$-CC@ VS$1(0.00916$ g) < VS4-CC@VS-2 (0.00972 g) < VS4-CC@VS-3 (0.01055) electrodes, respectively. The appropriate grown of $\mathrm{VS}_{4}$ on $\mathrm{CC}$ surface improved the wettability of the electrode and subsequently facilitate the mobility of the electrolyte ions through the entire electrode. ${ }^{[34]}$ The semicircle that denoted $R_{c t}$ in the equivalent circuit might be due to various factors such as electronic conductivity, arrangements of inter-particle in electrode and electrode surface features etc. The $\mathrm{R}_{\mathrm{ct}}$ values for $\mathrm{VS}_{4}-\mathrm{CC} @ \mathrm{VS}-1, \mathrm{VS}_{4}-\mathrm{CC} @ \mathrm{VS}-2$, and $\mathrm{VS}_{4}-\mathrm{CC} @ \mathrm{VS}-3$ SSC devices are 5.675, 3.8, and $3.25 \Omega \mathrm{cm}^{2}$, respectively. Consequently, the lower value of $R_{c t}$ designates the rapid charge transfer rate of ions in the electrolyte, which is indicating the better redox reaction properties of the electrode. ${ }^{[35]}$ The capacitive elements of the VS 4 -CC@VS-1, VS 4 -CC@ VS-2, 
and VS4-CC@VS-3 SSC devices are divided into CPEl and CPE2, which represents the double layer capacitance and pseudocapacitance of the symmetric supercapacitors. ${ }^{[36]}$ In addition, the Warburg resistance $\left(\mathrm{W}_{\mathrm{R}}\right)$ is associated with ionic diffusion over the electrode/electrolyte interfaces. The $\mathrm{W}_{\mathrm{R}}$ value of the $\mathrm{VS}_{4}-\mathrm{CC} @ \mathrm{VS}-3$ is smaller than $\mathrm{VS}_{4}-\mathrm{CC} @ \mathrm{VS}-1$ and $\mathrm{VS}_{4}-$ CC@VS-2 SSCs owing to the higher growth of $\mathrm{VS}_{4}$ on CC substrate, which in turn improve the diffusion and transport path of ions in the electrode surface ${ }^{[37]}$ Figure 5(h) shows the Bode plots of the VS4-CC@VS-1, VS 4 -CC@VS-2, and VS 4 -CC@VS-3 SSC devices and it reveals the phase angles values of $-49^{\circ},-64^{\circ}$, and $-72^{\circ}$ at low-frequency region $(10 \mathrm{mHz})$. The high phase angle value of the VS4-CC@VS-3 SSC again supports the excellent capacitance behavior than the other two devices. However, the phase angle value is comparatively lesser than that of an ideal capacitor $\left(-90^{\circ}\right)$ this deviation of value attributes the pseudocapacitive property of electrode materials. ${ }^{[33 b]}$ Further, the relaxation time constant $\left(\tau_{0}=1 / f_{o}\right), f_{o}$ denoted as a knee frequency (frequency at $-45^{\circ}$ ) is a significant characteristic of the supercapacitor device. The $\tau_{\mathrm{o}}$ values of the VS-CC@VS-1 ( $\left.\tau_{1}=3.185 \mathrm{~s}\right), \mathrm{VS}_{4}-\mathrm{CC} @ \mathrm{VS}-2\left(\tau_{2}=0.45 \mathrm{~s}\right)$, and VS 4 -CC@ VS-3 $\left(\tau_{3}=0.284 \mathrm{~s}\right)$ SSCs are $3.19,0.45$ and $0.28 \mathrm{~s}$, respectively. The lower relaxation time constant of $\mathrm{VS}_{4-}$ CC@ VS-3 device reveals the fast diffusion of ions from electrolyte intensely interacts with the electrode and reach the maximum capacitance with very fast recharging. ${ }^{[38]}$ The most important parameters such as energy density $\left(\mathrm{E}_{\mathrm{d}}\right)$ and power density $\left(\mathrm{P}_{\mathrm{d}}\right)$ of the $\mathrm{VS}_{4}$ CC@VS-1, VS 4 -CC@VS-2, and VS 4 -CC@VS-3-based SSCs were estimated and represented in Rogan plot (Figure 5(i)). The VS4-CC@VS-1 SSC device exhibits a maximum $\mathrm{E}_{\mathrm{d}}$ of $16.52 \mu \mathrm{Wh}$ $\mathrm{cm}^{-2}$ and $\mathrm{P}_{\mathrm{d}}$ of $9997 \mu \mathrm{W} \mathrm{\textrm {cm } ^ { - 2 }}$, respectively. Correspondingly, VS4-CC@VS-2 SSC shows a

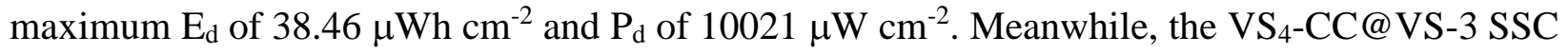
device displays the highest $E_{d}$ of $74.4 \mu \mathrm{Wh} \mathrm{cm}{ }^{-2}\left(28.6 \mathrm{Wh} \mathrm{kg}^{-1}\right)$ and $\mathrm{P}_{\mathrm{d}}$ of $10154 \mu \mathrm{W} \mathrm{cm} \mathrm{cm}^{-2}(9340$ 
$\mathrm{W} \mathrm{kg}^{-1}$ ), respectively. The maximum energy and power densities of the $\mathrm{VS}_{4}$-CC@VS-3 SSC further reveal the excellent performance of the device. The energy and power density values of the present work were compared with previous reports and presented in Table 1. Figure 5(j) displays the electrochemical merits of the laminated VS4-CC@VS-3 nanoflower on CC for electrochemical energy storage. The compact growth of $\mathrm{VS}_{4}$ nanoflower network on CC could be certified for the fast diffusion of electrolyte ions. From result, the hierarchical nanostructure of $\mathrm{VS}_{4}$ has shown nearly aggregated nanospikes, which can offer a short ionic interchange between the active material/electrolyte interfaces. Therefore, VS4-CC@VS-3 allows a rapid motion of electrons through the charge/discharge processes, which mainly improved areal capacitance $\left(\mathrm{C}_{\mathrm{ac}}\right)$, high rate performance and cycling stability, respectively. 

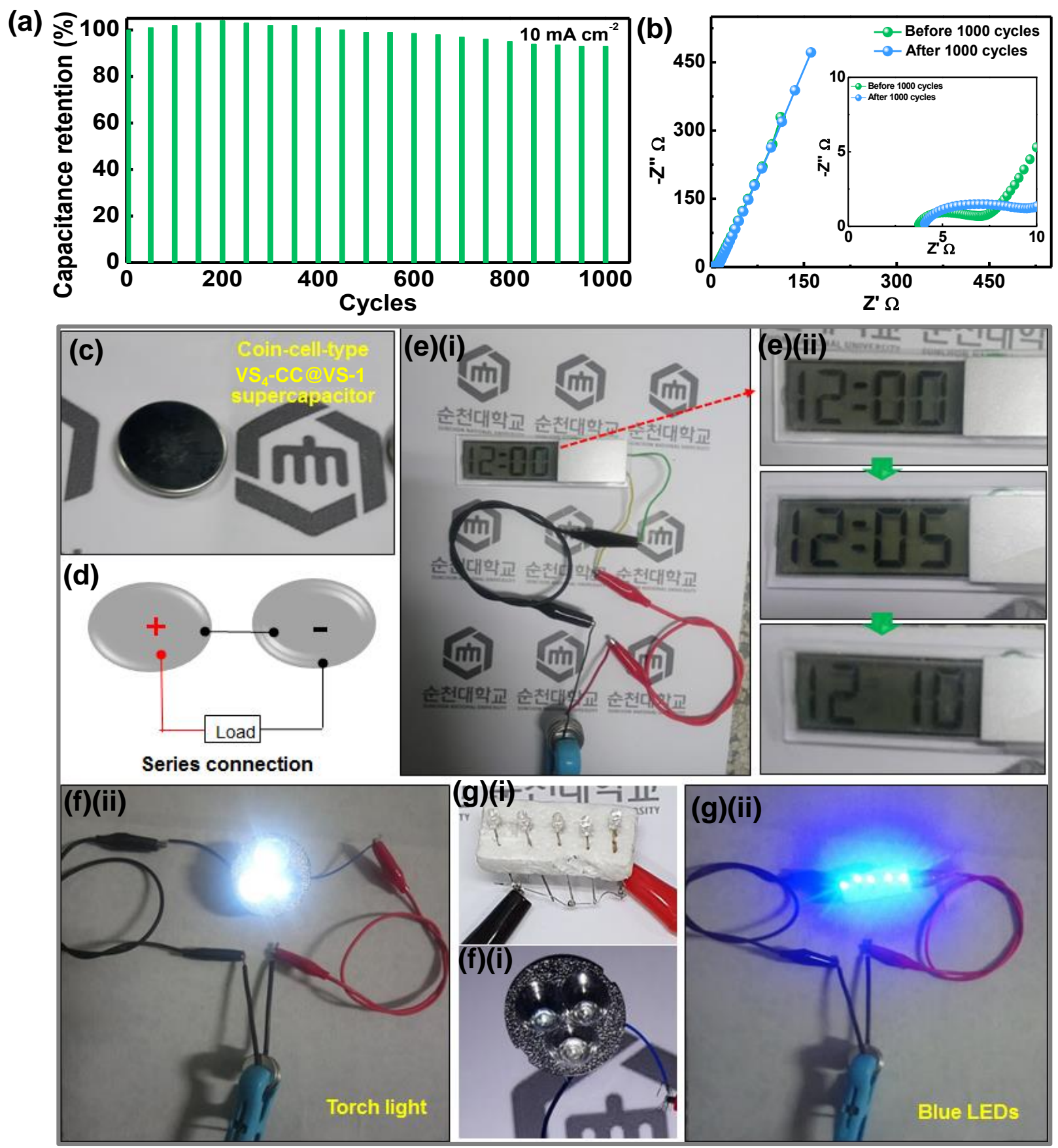

Figure 6 (a) Cycling stability of VS 4 -CC@VS-3 SSC device for 1000 charge/discharge cycles at $10 \mathrm{~mA} \mathrm{~cm}^{-2}$, (b) Nyquist plots of before and after cyclic stability test of VS 4 -CC@VS-3 SSC device, (c-d) Schematic and photographic image of the VS4-CC@VS-3//VS4-CC@VS-3 SSC device. (e) (i-ii) demonstrating of the two serially connected charged SSCs power a digital clock 
(inset shows the display of the clock for various durations). (d-e) (i-ii) powering commercial torch light and blue LEDs using two charged VS4-CC@VS-3 SSCs.

Cycling stability is another factor, which determines the device practical suitability for real-time applications. Figure 6(a) displays the cyclic stability plot of the VS4-CC@VS-3 SSC device for the first consecutive $1000 \mathrm{GCD}$ cycles at a current density of $10 \mathrm{~mA} \mathrm{~cm}{ }^{-2}$. As displayed in the figure that the SSC device represents better areal capacitance retention of $\sim 93 \%$ even after 1000 cycles. Furthermore, the stability of the VS4-CC@VS-3 SSC device had been examined through electrochemical impedance spectroscopy (EIS) of fresh and after cycling stability test. The corresponding EIS plots and fitted equivalent circuit are demonstrated in Figure 6(b) and Figure S7 (a). The corresponding fitted electric circuit parameters are listed in Table 3, which shows no significant difference in the EIS parameters of the device before and after cyclic stability test. Although, the slight increase in the $R_{\mathrm{s}}$ values (3.765 to $3.826-\Omega \mathrm{cm}^{2}$ ) after cyclic stability test, is mainly attributed to the scant poisoning of the ionic liquid electrolyte by consecutive charge/discharge process. Moreover, the $\mathrm{R}_{\mathrm{ct}}$ values slightly increases (3.25 to $4.515 \Omega \mathrm{cm}^{2}$ ) after stability test, which designates that the VS4-CC@VS-3 electrodes are slightly damaged during the 1000 consecutive GCD cycles in the wide potential window of $2 \mathrm{~V}$. Further confirming the stability of the electrode, the surface morphology of the electrode after stability test was examined through field emission scanning electron microscopy analysis as shown in Figure S8(c) (i-iii). The obtained FE-SEM images of the VS4-CC@VS-3 SSC electrode after stability clearly indicates that the electrode retains its novel self-assembled nanoflower structure with some slight fissure even after 1000 constant GCD cycles. This confirms the electrode has excellent stability in ionic liquid electrolyte even after 1000 GCD cycles. 
The real-time applications of the fabricated SSCs device were tested and depicted in Figure 7(ab). The figure shows the photographic images of the powered conventional portable devices and the schematic diagram of the two coin cell-type SSCs connected in series to increase the cell potential. After charging to $<3.2 \mathrm{~V}$ within $20 \mathrm{~s}$, the devices successfully powered a digital clock up to 10 mins, as shown in Figure 7(c)(i-ii). Furthermore, the high energy and power density of the SSCs energetically lighten up a three-point configuration torch light and five blue $(2.2 \mathrm{~V}$, 20mA) LEDs, as shown in Figure 7(d-e) (i-ii). The aforementioned electrochemical properties with practical demonstration signify that the uniform growth of VS4-CC@VS-3 flexible electrodes paves a way for the development of other metal chalcogenides for energy storage applications.

\section{Conclusion}

In conclusion, hierarchically structured binder-free $\mathrm{VS}_{4}$ nanostructures were successfully grown on the flexible $\mathrm{CC}$ under the controlled growth concentrations using a facile hydrothermal method. The optimized growth of the sample with beneficial properties of like high electrochemical activity, good redox performance and binder-free novel electrode material put a key role in elevating the electrochemical performance. Particularly, the fabricated VS4-CC@ VS3-based SSC revealed the maximum areal and gravimetric capacitance of $536 \mathrm{mF} \mathrm{cm}^{-2}$ and $206 \mathrm{~F}$ $\mathrm{g}^{-1}$ in ionic liquid electrolyte with a wide potential window $2 \mathrm{~V}$. Furthermore, the assembled SSC device demonstrated better electrochemical properties in terms of maximum energy density 74.4 $\mu \mathrm{Wh} \mathrm{cm} \mathrm{cm}^{-2}\left(28.6 \mathrm{Wh} \mathrm{kg}^{-1}\right)$ and power density $10154 \mu \mathrm{W} \mathrm{cm}{ }^{-2}\left(9340 \mathrm{~W} \mathrm{~kg}^{-1}\right)$ along with excellent cyclic retention of $93 \%$ after 1000 charge/discharge. Utilizing the maximum energy and power, the fabricated SSC device powered electronic gadgets like a digital clock and lightening LEDs, which demonstrate its potential capability for real-time applications. The improved energy 
storage performance with binder-free growth of metal chalcogenides-based electrodes may reveal better prospects for the development of high-performance electrochemical energy storage devices. Moreover, the study confirms 1-ethyl-3-methylimidazolium trifluoro methane sulfonate ([EMIM][OTf]) ionic liquid as a potential electrolyte for metal sulfide-based symmetric device with excellent electrochemical performances. Thus, this work considerably encourages the research and utilization of ionic liquid-based electrolyte in metal oxide or metal sulfide supercapacitors for achieving high energy/power density device for future energy storage systems.

\section{Experimental methods}

\subsection{Chemicals}

The starting materials $\mathrm{VOSO}_{4} \cdot \mathrm{xH}_{2} \mathrm{O}$ and thioacetamide $\left(\mathrm{C}_{2} \mathrm{H}_{5} \mathrm{NS}\right)$ were purchased from Aldrich Chemicals, the carbon fiber cloth (CC) was purchased from Foshan Energetic Film Co., Ltd., (China), nitric acid and ethanol were obtained from Sigma Aldrich Chemicals, the 1-ethyl-3methylimidazolium trifluoromethanesulfonate ([EmIm][OTf]) ionic liquid was purchased from Tokyo Chemical Industry co., Ltd., (Japan). All the above chemicals were of analytical grade and used without further purifications.

\subsection{Growth or deposition of patronite $\left(\mathrm{VS}_{4}\right)$ nanostructures on carbon fiber cloth (CC) substrate}

The binder-free growth of VS 4 -CC@VS-1, VS 4 -CC@VS-2 and VS 4 -CC@VS-3 electrodes were performed via a facile one-step hydrothermal method. Initially, the carbon cloth substrates (CCs) of dimension of $1 \times 1 \mathrm{~cm}^{2}$ were pretreated by dipping into the concentrated nitric acid at $70{ }^{\circ} \mathrm{C}$ and washed with deionized (DI) water several times to achieve neutral $\mathrm{pH}$ and dried at $90{ }^{\circ} \mathrm{C}$ for $12 \mathrm{~h}$ in a vacuum oven. The growth solution was prepared by dissolving calculated amounts of 
$\mathrm{VOSO}_{4} \cdot \mathrm{xH}_{2} \mathrm{O}, \mathrm{C}_{2} \mathrm{H}_{5} \mathrm{NS}$, and $\mathrm{CH}_{3} \mathrm{COOH}$ (complexing agent) materials in DI water and stirred for $1 \mathrm{~h}$ at room temperature (RT). These reagents with suitable portions were mixed in a glass beaker having $50 \mathrm{ml}$ of DI water under constant magnetic stirring until form a homogeneous blue solution at RT. Meanwhile, the pretreated CCs were immersed in the growth solution until complete absorption of the solution. Subsequently, the reaction solution with CC was transferred into a Teflon-lined stainless-steel autoclave and maintained at $160{ }^{\circ} \mathrm{C}$ in a muffle furnace for $16 \mathrm{~h}$. After completion of the hydrothermal reaction, the autoclave was naturally cool down to RT. Finally, the obtained dark black $\mathrm{VS}_{4}$ grown CCs substrates were washed several times with deionized (DI) water and dried at $80{ }^{\circ} \mathrm{C}$ in a vacuum oven for overnight. The samples synthesized with various growth solution concentration are labelled as VS4-CC@VS-1, VS 4 CC@VS-2 and VS4-CC@VS-3 corresponding to the mixture proportions $x \mathrm{VS}, 2 x \mathrm{VS}$ and $4 x \mathrm{VS}$ ( $x$ denote the quantity of precursors), respectively. The mass loading of $\mathrm{VS}_{4}$ on $\mathrm{CC}$ was determined to be $\sim 0.53, \sim 0.90$ and $\sim 1.30 \mathrm{mg} \mathrm{cm}^{-2}$ for $\mathrm{VS}_{4}-\mathrm{CC} @ \mathrm{VS}-1, \mathrm{VS}_{4}$-CC@ $@ \mathrm{VS}-2$ and $\mathrm{VS}_{4}$ CC@VS-3 respectively. For the TEM analysis, the VS4-CC@VS-3 sample was cut into small pieces and dispersed in distilled water under deep ultrasonication. The aqueous solution was then drop cast on the TEM grid and presented into the TEM chamber.

\subsection{Structural characterization}

X-ray diffraction patterns of the electrodes were collected (XRD, D/max-2400, Rigaku, Ultima IV) using $\mathrm{Cu} \mathrm{K \alpha}$ source operated at $40 \mathrm{kV}$ and $30 \mathrm{~mA}$ in the $2 \theta$ range $10-60^{\circ}$. X-ray Photoelectron Spectroscopy (XPS) measurement was performed by the Thermo Electron MultiLab2000 and pattern was collected using a $\mathrm{Al} \mathrm{K \alpha}$ radiation. The morphology of the synthesized nanostructures was observed using Field Emission Scanning Electron Microscopy (FESEM) and elemental mapping of the fabricated electrodes was performed using Hitachi- 
S4800 at an accelerating voltage of $3 \mathrm{kV}$. Transmission electron microscopy (TEM) images of VS3@CC sample was observed by dispersing nanoparticle in water solution by ultra-sonication and recorded utilizing JEOL model JEM- 2100F (Japan).

\subsection{Electrochemical measurements:}

The electrochemical properties of the synthesized VS4-CC@VS-1, VS4-CC@VS-2 and VS4-CC@VS-3 electrodes were investigated by using ZIVE-SP2 electrochemical workstation (Korea) at RT. Prior to the experiment, the $\mathrm{VS}_{4}-\mathrm{CC}$ electrodes were submerged in the electrolyte solution for $12 \mathrm{~h}$ under vacuum. The cyclic voltammetry of the VS-CC@VS-3 electrode were initially studied in a conventional three-electrode system, with the $\mathrm{VS}_{4}-\mathrm{CC} @ \mathrm{VS}-3$ as the working electrode, a platinum plate as the counter electrode and $\mathrm{Ag} / \mathrm{AgCl}$ as the reference electrode in 1M 1-ethyl-3-methylimidazolium trifluoromethanesulfonate ([EMIM][OTf]) ionic liquid (IL) in acetonitrile solution. The symmetric supercapacitors were fabricated utilizing a stainless-steel split test cell (EQSTC) from MTI Korea Ltd. The symmetric supercapacitor was designed by nearly similar weight of two as-prepared $\mathrm{VS}_{4}-\mathrm{CC}$ electrodes were set as a face to face sandwich type, which have been separated by a filter paper separator and filled with ILs electrolyte. Cyclic voltammetry (CV) was tested for different scan rates from 5 to $100 \mathrm{mV} \mathrm{s}^{-1}$ and the galvanostatic charge/discharge analysis was performed for various current densities $(1,2$, 4, 6, 8, and $\left.10 \mathrm{Ag}^{-1}\right)$ at a prolonged potential window of $2 \mathrm{~V}$. Electrochemical impedance spectroscopy (EIS) was characterized in the frequency range between $0.01 \mathrm{~Hz}-100 \mathrm{kHz}$ at $\mathrm{OV}$ bias condition with an $\mathrm{AC}$ perturbation of $10 \mathrm{mV}$.

The specific capacitance $\left(\mathrm{C}_{\mathrm{sc}}\right)$ and areal capacitance $\left(\mathrm{C}_{\mathrm{ac}}\right)$ of symmetric device was calculated by using a charge/discharge curves using Equation (2) and (3), 


$$
\begin{aligned}
& C_{s c}=2\left(\frac{I \Delta t}{m \Delta V}\right) \\
& C_{a c}=2\left(\frac{I \Delta t}{a \Delta V}\right)
\end{aligned}
$$

where, $I$ is the constant discharge current (mA), $\Delta t$ is the discharge time (s), $m$ is the mass of the one electrode $(\mathrm{g}), \mathrm{a}$ is the total active area of the electrodes $\left(\mathrm{cm}^{2}\right)$ and $\Delta V$ is the potential window $(\mathrm{V})$.

The energy density $\left(\mathrm{E}_{\mathrm{d}}\right)$ and the power density $\left(\mathrm{P}_{\mathrm{d}}\right)$ of the SSC were obtained from the Equations (2), (3) and (4),

$$
\begin{aligned}
& E_{d}=\frac{1}{8} C_{s p} \Delta V^{2} \\
& E_{d}=\frac{1}{8} C_{a c} \Delta V^{2} \\
& P_{d}=\frac{E}{\Delta t}
\end{aligned}
$$

\section{Acknowledgement}

This research was supported by Creative Materials Discovery Program through the National Research Foundation of Korea (NRF) funded by the Ministry of Science, ICT and Future (2015M3D1A1069710), and Basic Science Research Program through the National Research Foundation of Korea (NRF) funded by the Ministry of Education (NRF-2014R1A6A1030419).

This work was supported by the Spanish Government through Projects ENE2016-78933-C4-1-R, ENE2017-87671-C3-2-R. 


\section{Reference}

[1] S. Xie, F. Dong, J. Li, ChemistrySelect 2019, 4, 437.

[2] J. Li, C. Wei, Y. Sun, Q. Liu, X. Zhang, J. Guo, Advanced Materials Interfaces 2019, 6, 1801470.

[3] a) G. Nagaraju, S. C. Sekhar, J. S. Yu, Advanced Energy Materials 2018, 8, 1702201; b)

S. C. Sekhar, G. Nagaraju, B. Ramulu, J. S. Yu, ACS Applied Materials \& Interfaces 2018, 10, 36976; c) S. C. Sekhar, G. Nagaraju, J. S. Yu, Nano Energy 2017, 36, 58.

[4] a) J. Iqbal, A. Numan, S. Rafique, R. Jafer, S. Mohamad, K. Ramesh, S. Ramesh, Electrochimica Acta 2018, 278, 72; b) M. N. Rantho, M. J. Madito, N. Manyala, Electrochimica Acta 2018, 262, 82.

[5] S. Patil, A. Harle, S. Sathaye, K. Patil, CrystEngComm 2014, 16, 10845.

[6] R. Bhandavat, L. David, G. Singh, The Journal of Physical Chemistry Letters 2012, 3, 1523.

[7] S. Peng, L. Li, H. Tan, R. Cai, W. Shi, C. Li, S. G. Mhaisalkar, M. Srinivasan, S. Ramakrishna, Q. Yan, Advanced Functional Materials 2014, 24, 2155.

[8] D. T. Pham, B. Sambandam, S. Kim, J. Jo, S. Kim, S. Park, V. Mathew, Y.-K. Sun, K. Kim, J. Kim, Energy Storage Materials 2019, 19, 270.

[9] B. Pandit, L. K. Bommineedi, B. R. Sankapal, Journal of Energy Chemistry 2019, 31, 79.

[10] R. B. Rakhi, N. A. Alhebshi, D. H. Anjum, H. N. Alshareef, Journal of Materials Chemistry A 2014, 2, 16190.

[11] a) X. Y. Yu, X. W. Lou, Advanced Energy Materials 2018, 8, 1701592; b) W. Liu, H. Niu, J. Yang, K. Cheng, K. Ye, K. Zhu, G. Wang, D. Cao, J. Yan, Chemistry of Materials 

6, 23757; b) J. Feng, X. Sun, C. Wu, L. Peng, C. Lin, S. Hu, J. Yang, Y. Xie, Journal of the American Chemical Society 2011, 133, 17832.

[13] C. S. Rout, B.-H. Kim, X. Xu, J. Yang, H. Y. Jeong, D. Odkhuu, N. Park, J. Cho, H. S. Shin, Journal of the American Chemical Society 2013, 135, 8720.

[14] a) Z.-W. Peng, K.-F. Jun, H.-Y. Li, B. Xie, Cham 2019; b) G. Yang, B. Zhang, J. Feng, H. Wang, M. Ma, K. Huang, J. Liu, S. Madhavi, Z. Shen, Y. Huang, ACS Applied Materials \& Interfaces 2018, 10, 14727.

[15] a) L. Wu, Y. Zhang, B. Li, P. Wang, L. Fan, N. Zhang, K. Sun, Frontiers in Energy 2018, DOI: 10.1007/s11708-018-0576-9; b) Y. Zhou, J. Tian, H. Xu, J. Yang, Y. Qian, Energy Storage Materials 2017, 6, 149.

[16] a) M. Rajesh, C. J. Raj, R. Manikandan, B. C. Kim, S. Y. Park, K. H. Yu, Materials Today Energy 2017, 6, 96; b) S. Sun, J. Lang, R. Wang, L. Kong, X. Li, X. Yan, Journal of Materials Chemistry A 2014, 2, 14550; c) R. Manikandan, C. J. Raj, M. Rajesh, B. C. Kim, G. Nagaraju, W.-g. Lee, K. H. Yu, Journal of Materials Chemistry A 2018, 6, 11390.

[17] S. Britto, M. Leskes, X. Hua, C.-A. Hébert, H. S. Shin, S. Clarke, O. Borkiewicz, K. W. Chapman, R. Seshadri, J. Cho, C. P. Grey, Journal of the American Chemical Society 2015, 137, 8499 .

[18] a) Z. Yu, L. Tetard, L. Zhai, J. Thomas, Energy \& Environmental Science 2015, 8, 702; b) K. Zhu, Y. Wang, J. A. Tang, H. Qiu, X. Meng, Z. Gao, G. Chen, Y. Wei, Y. Gao, RSC 
Advances 2016, 6, 14819; c) Z. Zhang, H. Wang, Y. Zhang, X. Mu, B. Huang, J. Du, J. Zhou, X. Pan, E. Xie, Chemical Engineering Journal 2017, 325, 221; d) W. Li, L. Xin, X. Xu, Q. Liu, M. Zhang, S. Ding, M. Zhao, X. Lou, Scientific Reports 2015, 5, 9277; e) G. Nagaraju, R. Kakarla, S. M. Cha, J. S. Yu, Nano Res. 2015, 8, 3749; f) S. Gao, F. Liao, S. Ma, L. Zhu, M. Shao, Journal of Materials Chemistry A 2015, 3, 16520; g) G. Nagaraju, G. S. R. Raju, Y. H. Ko, J. S. Yu, Nanoscale 2016, 8, 812; h) S. M. Cha, G. Nagaraju, J. S. Yu, J. Phys. Chem. C 2016, DOI: 10.1021/acs.jpcc.6b04611.

[19] R. Newell, J. Faure-Vincent, B. Iliev, T. Schubert, D. Aradilla, Electrochimica Acta 2018, $267,15$.

[20] A. Eftekhari, Y. Liu, P. Chen, Journal of Power Sources 2016, 334, 221.

[21] C. Merlet, C. Péan, B. Rotenberg, P. A. Madden, P. Simon, M. Salanne, The Journal of Physical Chemistry Letters 2013, 4, 264.

[22] C. Merlet, B. Rotenberg, P. A. Madden, M. Salanne, Physical Chemistry Chemical Physics 2013, 15, 15781.

[23] M. V. Fedorov, A. A. Kornyshev, Chemical Reviews 2014, 114, 2978.

[24] A. C. Forse, J. M. Griffin, C. Merlet, P. M. Bayley, H. Wang, P. Simon, C. P. Grey, Journal of the American Chemical Society 2015, 137, 7231.

[25] T. T. Yu, H. L. Liu, M. Huang, J. H. Zhang, D. Q. Su, Z. H. Tang, J. F. Xie, Y. J. Liu, A. H. Yuan, Q. H. Kong, RSC Advances 2017, 7, 51807.

[26] S. Ratha, S. R. Marri, N. A. Lanzillo, S. Moshkalev, S. K. Nayak, J. N. Behera, C. S. Rout, Journal of Materials Chemistry A 2015, 3, 18874.

[27] A. Ganguly, S. Sharma, P. Papakonstantinou, J. Hamilton, 2013. 
[28] C. V. V. Muralee Gopi, S. Ravi, S. S. Rao, A. Eswar Reddy, H.-J. Kim, Scientific Reports 2017, 7, 46519 .

[29] M. Galiński, A. Lewandowski, I. Stępniak, Electrochimica Acta 2006, 51, 5567.

[30] X. Zhang, D. Zhao, Y. Zhao, P. Tang, Y. Shen, C. Xu, H. Li, Y. Xiao, Journal of Materials Chemistry A 2013, 1, 3706.

[31] G. S. Rama Raju, E. Pavitra, G. Nagaraju, S. C. Sekhar, S. M. Ghoreishian, C. H. Kwak, J. S. Yu, Y. S. Huh, Y.-K. Han, Journal of Materials Chemistry A 2018, 6, 13178.

[32] a) R. Manikandan, C. J. Raj, M. Rajesh, B. C. Kim, S. Park, K. H. Yu, Advanced Materials Interfaces 2018, 5, 1800041; b) C. J. Raj, M. Rajesh, R. Manikandan, K. H. Yu, J. R. Anusha, J. H. Ahn, D.-W. Kim, S. Y. Park, B. C. Kim, Journal of Power Sources 2018, 386, 66; c) M. Rajesh, C. Justin Raj, B. C. Kim, R. Manikandan, K. H. Kim, S. Y. Park, K. H. Yu, Electrochimica Acta 2017, 240, 231; d) S. Yu, Y. Zhang, G. Lou, Y. Wu, X. Zhu, H. Chen, Z. Shen, S. Fu, B. Bao, L. Wu, Scientific reports 2018, 8, 5246.

[33] a) R. Manikandan, C. J. Raj, M. Rajesh, B. C. Kim, J. Y. Sim, K. H. Yu, ChemElectroChem 2018, 5, 101; b) C. J. Raj, M. Rajesh, R. Manikandan, J. Y. Sim, K. H. Yu, S. Y. Park, J. H. Song, B. C. Kim, Electrochimica Acta 2017, 247, 949.

[34] A. Choudhury, B. Dey, S. S. Mahapatra, D.-W. Kim, K.-S. Yang, D.-J. Yang, Nanotechnology 2018, 29, 165401.

[35] R. Manikandan, C. Justin Raj, M. Rajesh, B. C. Kim, S. Y. Park, B.-B. Cho, K. H. Yu, Electrochimica Acta 2017, 230, 492.

[36] D. K. Kampouris, X. Ji, E. P. Randviir, C. E. Banks, RSC Advances 2015, 5, 12782.

[37] B. Saravanakumar, K. K. Purushothaman, G. Muralidharan, ACS Applied Materials \& Interfaces 2012, 4, 4484. 
[38] V. Sahu, S. Goel, R. K. Sharma, G. Singh, Nanoscale 2015, 7, 20642.

[39] J. Qi, X. Liu, Y. Sui, Y. He, Y. Ren, Q. Meng, F. Wei, X. Zhang, Journal of Materials Science: Materials in Electronics 2019, 30, 667.

[40] K. Guo, Y. Ma, H. Li, T. Zhai, Small 2016, 12, 1024.

[41] F. Wang, G. Li, J. Zheng, J. Ma, C. Yang, Q. Wang, RSC Advances 2018, 8, 38945.

[42] P. Pazhamalai, K. Krishnamoorthy, V. K. Mariappan, S. Sahoo, S. Manoharan, S.-J. Kim, Advanced Materials Interfaces 2018, 5, 1800055.

[43] T. N. Y. Khawula, K. Raju, P. J. Franklyn, I. Sigalas, K. I. Ozoemena, Journal of Materials Chemistry A 2016, 4, 6411.

[44] K. Krishnamoorthy, P. Pazhamalai, G. K. Veerasubramani, S. J. Kim, Journal of Power Sources 2016, 321, 112. 


\begin{tabular}{|c|c|c|c|c|c|c|}
\hline sample & $\mathrm{C}_{\mathrm{sc}}$ or $\mathrm{C}_{\mathrm{ac}}$ & Voltage & Electrolyte & Energy density & Power density & Ref. \\
\hline $\begin{array}{c}\mathrm{NW@} \\
\mathrm{CuCo}_{2} \mathrm{~S}_{4}\end{array}$ & $35.8 \mathrm{mF} \mathrm{cm}^{-2}$ & $1.2 \mathrm{~V}$ & PVA-KOH gel & $7.2 \mu \mathrm{Wh} \mathrm{cm}^{-2}$ & - & [39] \\
\hline $\mathrm{Ti} @ \mathrm{MnO}_{2}$ & $15.6 \mathrm{mF} \mathrm{cm}^{-2}$ & $0.8 \mathrm{~V}$ & $1 \mathrm{M} \mathrm{LiCl}$ & $1.4 \mu \mathrm{Wh} \mathrm{cm}^{-2}$ & $580 \mu \mathrm{W} \mathrm{cm}{ }^{-2}$ & [40] \\
\hline $\mathrm{CNT} / \mathrm{CoS}$ & $288.43 \mathrm{~F} \mathrm{~g}^{-1}$ & $0.8 \mathrm{~V}$ & Polysulfide & $25.63 \mathrm{Wh} \mathrm{kg}^{-1}$ & $145.45 \mathrm{~W} \mathrm{~kg}^{-1}$ & {$[28]$} \\
\hline $\mathrm{CNT} / \mathrm{CuS}$ & $176.2 \mathrm{~F} \mathrm{~g}^{-1}$ & $0.8 \mathrm{~V}$ & Polysulfide & $15.66 \mathrm{Wh} \mathrm{kg}^{-1}$ & $145.45 \mathrm{~W} \mathrm{~kg}^{-1}$ & [28] \\
\hline $\mathrm{CNT} / \mathrm{PbS}$ & $101 \mathrm{~F} \mathrm{~g}^{-1}$ & $0.8 \mathrm{~V}$ & Polysulfide & $9.06 \mathrm{Wh} \mathrm{kg}^{-1}$ & $145.45 \mathrm{~W} \mathrm{~kg}^{-1}$ & {$[28]$} \\
\hline $\mathrm{MoS}_{2}-16$ & $45.7 \mathrm{~F} \mathrm{~g}^{-1}$ & $1.4 \mathrm{~V}$ & $1 \mathrm{M} \mathrm{Na}_{2} \mathrm{SO}_{4}$ & $12.46 \mathrm{~W} \mathrm{~h} \mathrm{~kg}^{-1}$ & $7000 \mathrm{~W} \mathrm{~kg}^{-1}$ & {$[41]$} \\
\hline $\begin{array}{l}\mathrm{MoSe}_{2} \\
\text { SCSPC }\end{array}$ & $18.93 \mathrm{mF} \mathrm{cm}^{-2}$ & $2 \mathrm{~V}$ & $\begin{array}{c}\text { PVDF-co-HFP/ } \\
\text { TEABF4 gel }\end{array}$ & $37.90 \mathrm{~mJ} \mathrm{~cm}^{-2}$ & - & [42] \\
\hline $\mathrm{f}-\mathrm{MoS}_{2} / \mathrm{CNS}$ & $231 \mathrm{Fg}^{-1}$ & $0.9 \mathrm{~V}$ & $1 \mathrm{M} \mathrm{Na}_{2} \mathrm{SO}_{4}$ & $26 \mathrm{Wh} \mathrm{kg}^{-1}$ & $6443 \mathrm{~W} \mathrm{~kg}^{-1}$ & {$[43]$} \\
\hline s-MoS $/$ CNS & $108 \mathrm{~F} \mathrm{~g}^{-1}$ & $0.7 \mathrm{~V}$ & $1 \mathrm{M} \mathrm{Na}_{2} \mathrm{SO}_{4}$ & $7.4 \mathrm{Wh} \mathrm{kg}^{-1}$ & $3700 \mathrm{~W} \mathrm{~kg}^{-1}$ & [43] \\
\hline $\mathrm{s}-\mathrm{MoS}_{2}$ & $195 \mathrm{Fg}^{-1}$ & $1 \mathrm{~V}$ & $1 \mathrm{M} \mathrm{Na}_{2} \mathrm{SO}_{4}$ & $27 \mathrm{Wh} \mathrm{kg}^{-1}$ & $8750 \mathrm{~W} \mathrm{~kg}^{-1}$ & {$[43]$} \\
\hline f-MoS 2 & $96 \mathrm{Fg}^{-1}$ & $0.8 \mathrm{~V}$ & $1 \mathrm{M} \mathrm{Na}_{2} \mathrm{SO}_{4}$ & $8.9 \mathrm{Wh} \mathrm{kg}^{-1}$ & $4000 \mathrm{~W}$ kg-1 & [43] \\
\hline $\mathrm{MoS}_{2} \mathrm{WSCs}$ & $119 \mu \mathrm{F} \mathrm{cm}^{-1}$ & $0.7 \mathrm{~V}$ & PVA-LiOH gel & $8.1 \mathrm{nW} \mathrm{h} \mathrm{cm}^{-1}$ & $145 \mu \mathrm{W} \mathrm{cm}{ }^{-1}$ & [44] \\
\hline $\mathrm{V}_{3} \mathrm{O}_{7} / \mathrm{CFC}$ & $178 \mathrm{Fg}^{-1}$ & $2 \mathrm{~V}$ & $\begin{array}{c}\text { [EMIM][OTf] } \\
\text { ionic liquid }\end{array}$ & $24.7 \mathrm{Wh} \mathrm{kg}^{-1}$ & $5128 \mathrm{~W} \mathrm{~kg}^{-1}$ & {$[16 \mathrm{cc}]$} \\
\hline $\mathrm{VS}_{4}-\mathrm{CC} @ \mathrm{VS}-3$ & $\begin{array}{c}536 \mathrm{mF} \mathrm{cm}^{-2} \\
\left(206 \mathrm{~F} \mathrm{~g}^{-1}\right)\end{array}$ & $2 \mathrm{~V}$ & $\begin{array}{c}\text { [EMIM][OTf] } \\
\text { ionic liquid }\end{array}$ & $\begin{array}{l}74.4 \mu \mathrm{Wh} \mathrm{cm}^{-2} \\
\left(28.6 \mathrm{Wh} \mathrm{kg}^{-1}\right)\end{array}$ & $\begin{array}{l}10154 \mu \mathrm{W} \mathrm{cm}-2 \\
\left(9340 \mathrm{~W} \mathrm{~kg}^{-1}\right)\end{array}$ & $\begin{array}{l}\text { This } \\
\text { work }\end{array}$ \\
\hline
\end{tabular}

Table 1. Comparison of the performances of the SSC device of present work with other reported metal sulphides/oxides based SSCs. 
Table.2 EIS fitted parameters of VS4-CC@VS-1, VS4-CC@VS-2 and VS4-CC@VS-3-based SSC.

\begin{tabular}{cccc}
\hline Parameters & VS 4 -CC@ VS-1 & VS 4 -CC@ VS-2 & VS 4 -CC $@$ VS-3 \\
\hline $\mathrm{R}_{s} / \boldsymbol{\Omega} \mathrm{cm}^{2}$ & 4.629 & 4.14 & 3.765 \\
$\mathrm{R}_{\mathrm{c}} / \mathbf{\Omega} \mathrm{cm}^{2}$ & 5.675 & 3.8 & 3.25 \\
$\mathrm{C}_{\mathrm{d} /} / \mathrm{mF} \mathrm{cm}^{-2}$ & 2.35 & 4.65 & 6.432 \\
$\mathrm{C}_{\mathrm{PE}} / \mathrm{mF} \mathrm{cm}^{-2}$ & 1.4 & 2.6 & 5.06 \\
$\mathrm{~W} / \boldsymbol{\Omega} \mathrm{cm}^{2}$ & 6.25 & 4.25 & 3.12 \\
\hline
\end{tabular}

Table.3 EIS fitted parameters of the VS4-CC@VS-3-based SSC before and after 1000 charge/discharge cycles.

\begin{tabular}{ccc}
\hline Parameters & $\begin{array}{c}\text { before } \\
\mathbf{1 0 0 0} \\
\text { GCD cycles }\end{array}$ & $\begin{array}{c}\text { after } \\
\mathbf{1 0 0 0} \\
\text { GCD cycles }\end{array}$ \\
\hline $\mathrm{R}_{\mathrm{S}} / \Omega \mathrm{cm}^{2}$ & 3.765 & 3.826 \\
$\mathrm{R}_{\mathrm{c} t} / \Omega \mathrm{cm}^{2}$ & 3.25 & 4.515 \\
$\mathrm{C}_{\mathrm{d}} / \mathrm{mF} \mathrm{cm}^{2}$ & 6.432 & 5.213 \\
$\mathrm{CPE}_{\mathrm{PE}} / \mathrm{mF} \mathrm{cm}^{-2}$ & 5.06 & 4.625 \\
$\mathrm{~W}_{\mathrm{R}} / \Omega \mathrm{cm}^{2}$ & 3.12 & 3.178 \\
\hline
\end{tabular}




\section{Table of content}

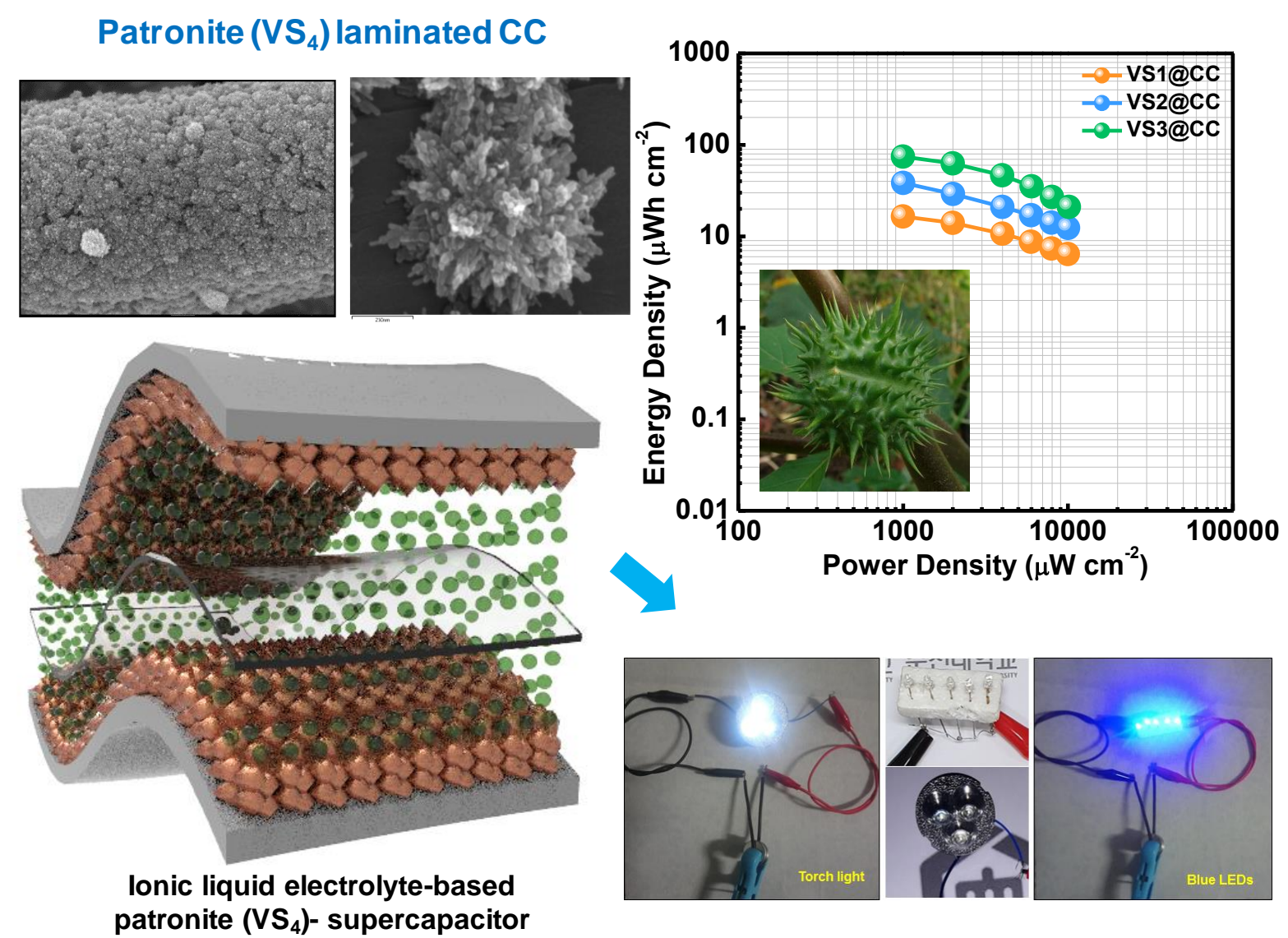




\section{Click here to access/download \\ Supporting Information Supporting Information.docx}

